\title{
Connection between the Asian Summer Monsoon and Stratosphere-Troposphere Circulation over the Asian Region
}

\author{
Makoto INOUE \\ Center for Climate System Research, University of Tokyo, Japan \\ Masaaki TAKAHASHI \\ Center for Climate System Research, University of Tokyo, Japan \\ (Manuscript received 3 April 2008, in final form 4 November 2008)
}

\begin{abstract}
We examined the connection between the Asian summer monsoon and stratosphere-troposphere circulation over the Asian region during a 25-year period (1980-2004) in boreal summer (June-August) using NCEP/ NCAR reanalysis data. Strong monsoon years (6 years) were extracted from the 25 -year sample using the monsoon index of Webster and Yang (1992), and composite maps of selected variables were created.

Analyses revealed significant positive geopotential height anomalies over Japan and over Iran around $100 \mathrm{hPa}$ in strong monsoon years. Both stretching and horizontal advection terms were dominant in the vorticity budget of high pressure anomalies over Japan, whereas only horizontal advection term was dominant over Iran. Wave activity flux was calculated for the strong monsoon years. Upward wave fluxes occurred over the Aral Sea and over Mongolia, in association with precipitation in northern India and in the Philippines. These correspondences are likely to show the Rossby wave response to diabatic heating in the Asian monsoon regions. Energy conversion was estimated in both East Asia and Central Asia using an equation for the rate of change of perturbation total energy. In East Asia, barotropic energy conversion was positive in the low-latitude lower troposphere. In midlatitudes, baroclinic energy conversion was positive in the troposphere. These results correspond to northward wave fluxes in the tropical lower troposphere and upward wave fluxes in mid-latitudes. In Central Asia, barotropic energy conversion was more dominant than baroclinic energy conversion in mid-latitudes. Upward fluxes occur in mid-latitudes, whereas northward fluxes do not occur in the tropics, unlike in East Asia. The estimation of the total wavenumber of stationary Rossby waves indicates that precipitation in the Philippines is strongly connected with high pressure anomalies over Japan through internal Rossby waves. In contrast, high pressure anomalies over Iran do not seem to be deeply related to precipitation in India.

These results suggest that lower stratospheric high pressure anomalies over Japan are connected with both Rossby waves generated through precipitation in the Philippines and baroclinic energy conversion over Mongolia, whereas high pressure anomalies over Iran are controlled profoundly by internal dynamical processes near the Aral Sea.
\end{abstract}

\section{Introduction}

Many studies have investigated the relationships between stratospheric phenomena and tropospheric

Corresponding author: Makoto Inoue, Center for Climate System Research, University of Tokyo, 5-1-5 Kashiwanoha Kashiwa-shi, Chiba 277-8568 Japan. E-mail: otenki@ccsr.u-tokyo.ac.jp

(C) 2009, Meteorological Society of Japan circulation in northern winter. Thompson and Wallace $(1998,2000)$ showed that the monthly variation in the Northern Hemisphere is dominated by a nearly zonally symmetric, north-south movement of momentum and mass across the mid-latitudes. This mode is referred to as the North Annular Mode (NAM). Limpasuvan and Hartmann (1999, 2000) indicated that variation in the NAM is forced mainly by eddy fluxes of stationary waves in the 
free troposphere of the Northern Hemisphere. In particular, the strength of the stratospheric polar vortex during winter is strongly connected with the tropospheric NAM by planetary wave propagation characteristics. Holton and Tan (1980, 1982) showed that the polar night jet was weaker (stronger) during the easterly (westerly) phase of the $50 \mathrm{hPa}$ equatorial quasi-biennial oscillation in northern winter. Analyses using a general circulation model (GCM) also follow this result (Niwano and Takahaski 1998). Boville (1984) showed that changes in wave-zonal flow interaction in the stratosphere are accompanied by alterations in wavenumber truncation and the top-level altitude in the stratosphere and that variation in the polar night jet significantly affects tropospheric circulation. Thus, the effects of the stratosphere on the tropospheric circulation field depend on the interaction of the vertical and horizontal propagation of Rossby waves with the mean flow.

However, whereas numerous studies have examined stratosphere-troposphere coupling in northern winter, few have looked at this interaction in northern summer, possibly because easterly wind ordinarily dominates, in theory, and stationary Rossby waves cannot propagate in the stratosphere in northern summer. Furthermore, studies of the coupling in northern summer have mainly focused on the tropopause region over the monsoon areas, particularly over the Tibetan Plateau. The Tibetan Plateau area is likely one of the most active stratosphere-troposphere coupling regions in northern summer because the tropopause in midlatitudes is raised in this area due to the Tibetan Plateau, which acts as a heat source in northern summer. Using climatological meridional wind data in the monsoon region, Dunkerton (1995) suggested that Rossby wave breaking events at the critical latitude may play an important role in mass transport to the lower stratosphere. Chen (1995) revealed that active stratosphere-troposphere mass exchange takes place during the summer Asian and Mexican monsoons, using a semi-Lagrangian transport model and wind data from the European Center for Medium-Range Weather Forecasts (ECMWF). Chen indicated that stratospheretroposphere exchange associated with Asian and Mexican monsoons is a two-way process, with tracers entering the extratropical stratosphere and vice versa. Moreover, studies have examined stratosphere-troposphere exchange of mass or water vapor through interaction with mid-latitude synoptic disturbances and with the Tibetan High (e.g., Dethof et al. 1999; Terao 1999). Thus some studies of stratosphere-troposphere coupling have focused on the transport of mass or constituents, as well as dynamical processes.

In contrast, many studies have examined summer weather and upper atmospheric fields in the vicinity of Japan. A key discovery was that of the PacificJapan (PJ) pattern by Nitta (1987). Nitta (1987) showed high (low) pressure anomalies in the vicinity of Japan when convection in the western tropical Pacific was active (inactive), which tended to cause hot (cold) summer conditions in Japan. These pressure anomalies, formed near East Asia through stationary Rossby waves from the active convection zone in the tropics, are referred to as the PJ pattern. Kosaka and Nakamura (2006) revealed the structure of the PJ pattern using composite analysis of active convection months near the Philippines. In addition, their estimations of energy conversion suggested that the PJ pattern may be regarded as a dynamical mode sustained by moist processes. Their study was based on anomalies from the basic field. In contrast, using climatological data, Enomoto et al. (2003) indicated that the formation of high pressure over Japan depends on Rossby wave propagation along the Asian jet in midsummer, a process referred to as the Silk Road pattern. Wakabayashi and Kawamura (2004) extracted four teleconnection patterns associated with anomalous summer climate by applying empirical orthogonal function (EOF) and regression analyses to stream function anomalies. Two of these patterns appear to correspond to the PJ and Silk Road patterns. Some researchers also investigated the connection between local precipitation distribution over the Asian region and circulation fields in the upper troposphere (Yatagai and Yasunari 1995; Iwao and Takahashi 2006, 2008). Moreover, recent studies suggest that circumglobal teleconnection in northern summer has significant correlations with the Indian summer monsoon (Ding and Wang 2005; Ding 2007).

In this paper, the connection between the Asian summer monsoon and atmospheric field in both the troposphere and stratosphere over a broad region, including Central Asia and East Asia, is examined statistically. We aim to clarify the horizontal and vertical structures and their mechanisms as associated with monsoon strength using budget analyses and wave activity flux analysis. This paper is organized as follows. After an introduction of the 
data used and the analysis method, including a definition of the monsoon index in Section 2, climatological fields over the monsoon region are discussed in Section 3. In Section 4, the results of composite analysis, EOF analysis, vorticity and heat budget analyses, wave activity flux analysis, and energy analysis are presented and interpreted. Summary and discussion are provided in Section 5 .

\section{Data and analysis method}

\subsection{Data}

The monthly precipitation data from 1980 to 2004 , with the horizontal resolution of $2.5^{\circ} \times 2.5^{\circ}$, were obtained from the Climate Prediction Center (CPC) Merged Analysis of Precipitation (CMAP; Xie and Arkin 1997). Four-times-daily reanalysis data with the horizontal resolution of $2.5^{\circ} \times 2.5^{\circ}$ from the National Centers for Environmental Prediction/National Center for Atmospheric Research (NCEP/NCAR) global atmospheric reanalysis data (Kalnay et al. 1996) were used for the meteorological field analysis from 1980 to 2004 .

\subsection{Definition of the Monsoon Index and resulting classification}

First, we extract strong (6 years) and weak (6 years) monsoon years in the 25-year study period (1980-2004) using the Monsoon Index proposed by Webster and Yang (1992). The index is based on the vertical shear $(850 \mathrm{hPa}$ zonal wind minus $200 \mathrm{hPa}$ zonal wind) in the monsoon region $\left(0^{\circ}-\right.$ $20^{\circ} \mathrm{N}, 40^{\circ}-110^{\circ} \mathrm{E}$ ) in June through August. Figure 1 shows interannual variation of the Monsoon Index; positive values represent strong summer monsoon years. Classification based on this index reveals strong monsoon years in 1980, 1981, 1984, 1985, 1990, and 1994, and weak monsoon years in 1983, 1987, 1992, 1996, 1997, and 2003. The following analyses mainly focus on the strong monsoon years.

The anomaly fields in strong or weak monsoon years are based on departures from the climatological fields defined as the average from 1980 to 2004.

\subsection{Analysis procedure}

We create composite maps for selected variables to investigate the statistical connection between the Asian summer monsoon and tropospheric and stratospheric circulations. In addition, local significance values were estimated based on t-tests. Significant regions reaching the $95 \%$ confidence level are also shown on the composite maps. The EOF analysis is then applied to extract major patterns

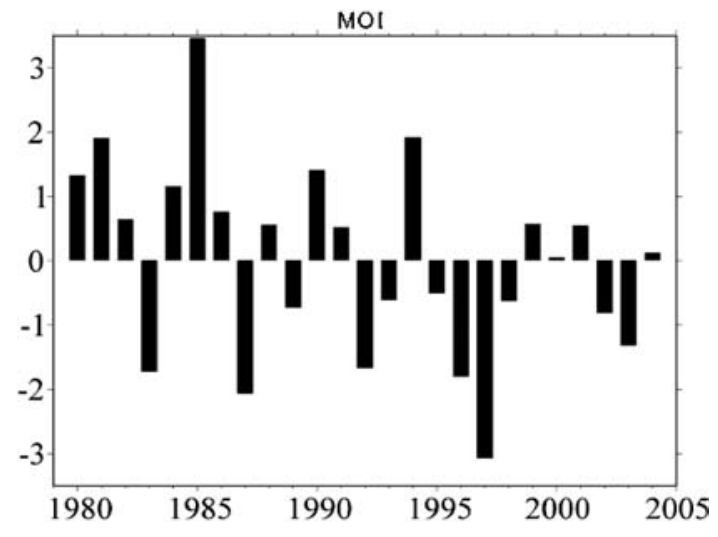

Fig. 1. Interannual variation of Monsoon Index by Webster and Yang (1992). The index is based on vertical shear $(850 \mathrm{hPa}$ zonal wind minus $200 \mathrm{hPa}$ zonal wind) on the monsoon region $\left(0^{\circ}-20^{\circ} \mathrm{N}, 40^{\circ}-110^{\circ} \mathrm{E}\right)$ in June-August. The unit is $\mathrm{m} \mathrm{s}^{-1}$.

associated with the monsoon strength in northern summer, similar to the studies by, e.g., Wakabayashi and Kawamura (2004); Sato and Takahashi (2006); Iwao and Takahaski (2008). Furthermore, the budget analyses for vorticity and heat balance are performed to account for the distribution of pressure and potential temperature anomalies and investigate the formation processes of the associated circulation pattern in the upper troposphere and stratosphere. In addition, the wave activity fluxes proposed by Takaya and Nakamura (2001) are calculated to quantitatively estimate the quasistationary Rossby wave propagation.

\section{Climatological fields}

Before the anomaly fields are analyzed, we investigate the climatological fields over the Asian monsoon region in June through August from 1980 to 2004. Figure 2 shows the climatological fields of geopotential height at $100 \mathrm{hPa}$, vertical p-velocity at $500 \mathrm{hPa}$, temperature at $300 \mathrm{hPa}$, surface precipitation, total wavenumber of stationary Rossby wave $K$ at $850 \mathrm{hPa}$, and latitude-pressure crosssection of zonal wind averaged for $50^{\circ}-150^{\circ} \mathrm{E}$. The total wavenumber $K$ was estimated as

$$
K^{2}=\frac{\overline{q_{y}}}{\overline{u_{g}}}-\frac{\varepsilon}{4 H^{2}},
$$

where $\overline{q_{y}}$ denotes the climatological meridional gradient of quasi-geostrophic potential vorticity, $H$ is the constant scale height, $\overline{u_{g}}$ is the climatological 
(a) $Z 100$

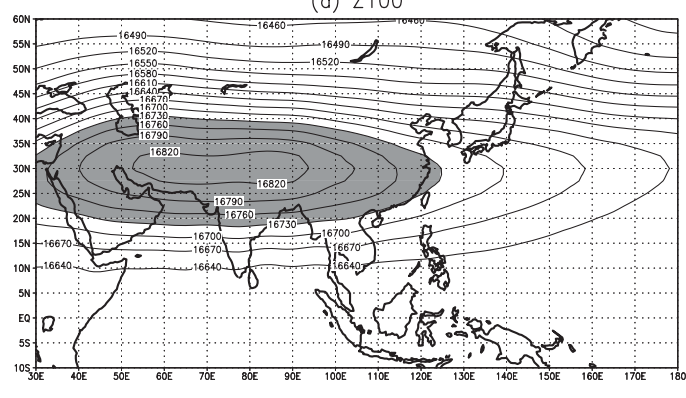

$\overbrace{16730}$

(c) $T 300$

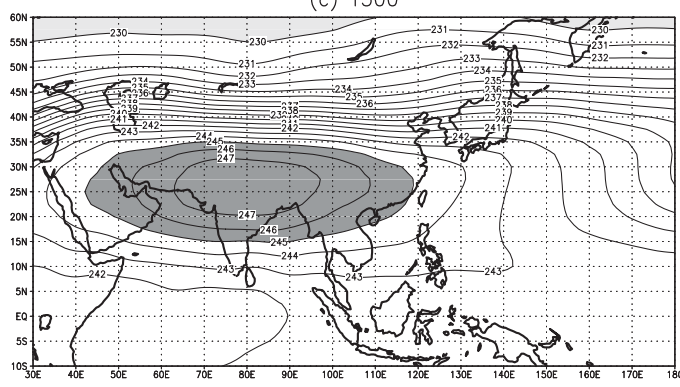

$\frac{1}{230} \frac{1}{245}$

(e) $K 850$

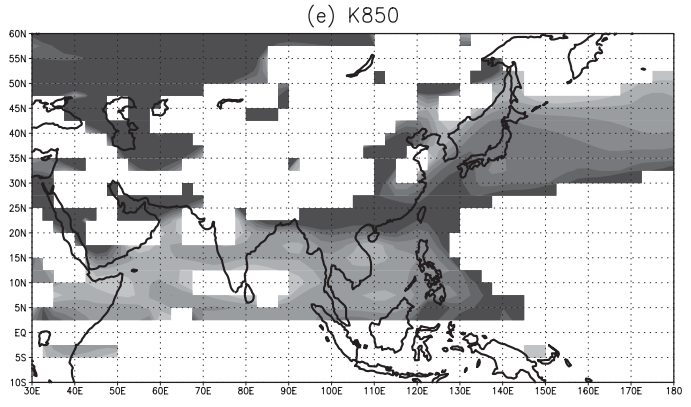

\begin{tabular}{l|llll}
1 & $\frac{1}{1.5}$ & $\frac{1}{2}$ & $\frac{1}{3}$ & $\frac{1}{4}$
\end{tabular} (b) omega500

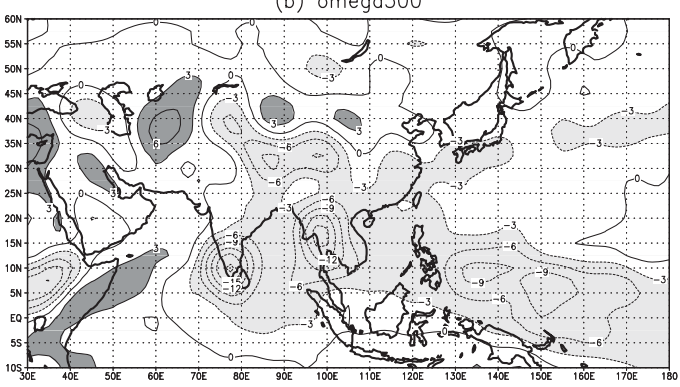

$\frac{1}{3}+3_{3}$

(d) $\operatorname{Prcp}$

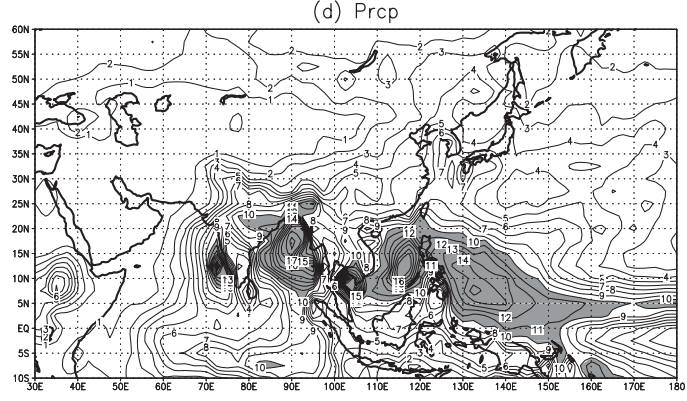

$\overbrace{10}$

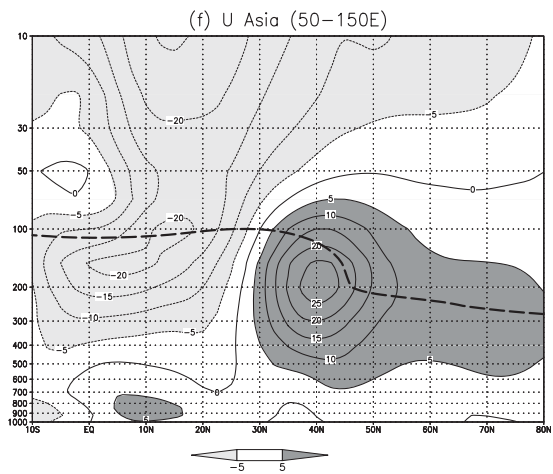

Fig. 2. Climatological fields of (a) geopotential height at $100 \mathrm{hPa},(\mathrm{b})$ vertical p-velocity at $500 \mathrm{hPa}$, (c) temperature at $300 \mathrm{hPa},(\mathrm{d})$ surface precipitation, and (e) total wavenumber of stationary Rossby waves $K$ at $850 \mathrm{hPa}$ in June-August for 1980-2004. The units are (a) m, (b) $10^{-2} \mathrm{~Pa} \mathrm{~s}^{-1}$, (c) K, (d) $\mathrm{mm} \mathrm{day}^{-1}$ and (e) $10^{-6} \mathrm{~m}^{-1}$. For (e) $K$, areas with imaginary numbers are not shaded. (f) Latitude-pressure cross-section of climatological field of zonal wind averaged for $50^{\circ}-150^{\circ} \mathrm{E}$ in June-August for $1980-2004$. The unit is $\mathrm{m} \mathrm{s}^{-1}$. The dashed line shows the tropopause.

geostrophic zonal wind, and $\varepsilon=\frac{f_{0}^{2}}{N^{2}}$ is the ratio of the Coriolis parameter squared to the BruntVaisala frequency squared in the climatological field. This equation is often used to represent the mean-flow properties with respect to the propagation of stationary Rossby waves (e.g., Nishii and Nakamura 2005; Iwao and Takahashi 2008).
Figure 2a shows the climatological geopotential height at $100 \mathrm{hPa}$. The Tibetan high is centered over the Tibetan Plateau and neighboring area, covering a large part of the subtropics in the Northern Hemisphere. The Tibetan high extends to the west of India, and can be interpreted as a Rossby wave response to the heating over India (Gill 
1980). The warm area at $300 \mathrm{hPa}$ is also centered over the Tibetan Plateau (Fig. 2c). As discussed later, this climatological field, particularly the longitudinal gradient of temperature near $20^{\circ}-40^{\circ} \mathrm{N}$, is critically important to the difference in energetics between East Asia and Central Asia in the anomaly field. Figure $2 \mathrm{~b}$ shows the vertical p-velocity at $500 \mathrm{hPa}$. Ascent regions are seen over a part of India, the Indochina Peninsula and east of the Philippines. These ascent regions correspond to those of much precipitation over the Philippines and over India (Fig. 2d). Strong descent regions are seen over the eastern Mediterranean Sea and over the Kyzylkum Desert, southeast of the Aral Sea. Rodwell and Hoskins (1996) discussed that the location of descent over the subtropical deserts may be determined by the orography. They showed that approximately half of the descent over the subtropical deserts is caused by the mid-latitude westerlies gliding down the sloping isentropes; consequently, the descent is enhanced and localized further by radiative cooling over the arid region. On the other hand, Enomoto et al. (2003) suggested that regions that have local adiabatic descent act as major Rossby wave sources and that the Bonin High near Japan forms as a result of the propagation of stationary Rossby waves along the Asian jet in the upper troposphere.

Next, we focus on the horizontal distribution of the climatological fields in the lower troposphere. Figure 2e shows that the distribution of the total wavenumber of stationary Rossby waves at $850 \mathrm{hPa}$ differs greatly between East Asia and Central Asia. The Arabian Sea is more favorable for the propagation of stationary Rossby waves than Central Asia in mid-latitudes. This may imply that Rossby waves tend to be trapped along the Somali jet in the lower troposphere. In contrast, imaginary numbers of $K$ prevail in the region from the northern India to the Aral Sea. Apparently, East Asia is more favorable for the propagation of Rossby wave than Central Asia in mid-latitudes. As discussed later, this difference is very important for explaining the difference in circulation anomaly fields over East Asia and over Central Asia. The latitudepressure distribution of zonal wind in East Asia (Fig. 2f) shows that in the tropics and subtropics, easterlies are dominant except at approximately $10^{\circ} \mathrm{N}$ in the lower troposphere. At mid-latitudes, westerly winds are seen from the lower troposphere to approximately $70 \mathrm{hPa}$ in the lower stratosphere, and easterlies appear above $50 \mathrm{hPa}$. Therefore, cou- pling between the troposphere and lower stratosphere can occur through planetary wave propagation in northern mid-latitudes over the Asian region during summer. We focus on circulation field anomalies of this westerly area in the lower stratosphere in the next section.

\section{Monsoon effects on the atmospheric field over the asian region}

\subsection{Anomaly fields in strong and weak monsoon years}

Figure $3 \mathrm{a}$ shows the longitude-pressure crosssection of zonal wind anomalies at $30^{\circ} \mathrm{N}$, representing the southern periphery of the Tibetan High, in strong monsoon years. The figure indicates a bimodal distribution of significant easterly wind anomalies around northern India $\left(\sim 80^{\circ} \mathrm{E}\right)$ and $\mathrm{Ja}-$ pan $\left(\sim 130^{\circ} \mathrm{E}\right)$ from the troposphere to the lower stratosphere. In particular, significant anomalies near northern India reach the $10 \mathrm{hPa}$ level. In comparison, Zhang et al. $(2006,2008)$ examined the seasonal evolution of the upper tropospheric westerly jet core around the northern periphery of the Tibetan High. Their results represent the core of the East Asian subtropical westerly jet, showing that the maximum westerly over East Asia is located near $140^{\circ} \mathrm{E}$ before July and near $90^{\circ} \mathrm{E}$ in July and August. This indicates a rapid seasonal eastwest displacement of the jet core between June and July. They concluded that diabatic heating changes are the primary factor determining the seasonal evolution of the westerly jet core over East Asia. If the zonal wind in this region is averaged from June to August, these westerly winds would show a bimodal distribution in the climatological field, being consistent with our result in the anomaly field. In other words, the Asian monsoon significantly weakens the subtropical westerly jet at $\sim 80^{\circ} \mathrm{E}$ and at $\sim 130^{\circ} \mathrm{E}$.

The distribution of precipitation anomalies indicates positive anomalies over the Philippines and over the region from northern India through Myanmar. This is consistent with that of ascent anomalies in the middle troposphere (Figs. $3 \mathrm{~b}$ and $3 \mathrm{~d}$ ). In contrast, negative precipitation anomalies and descent anomalies exist along $25^{\circ}-35^{\circ} \mathrm{N}$ from south China to south Japan. This represents inactive Baiu front coinciding with active convection over the Philippine Sea. This is again consistent with the findings by Rodwell and Hoskins (1996) as noted in Section 3. Vertical p-velocity anomalies are not positive over the Aral Sea (Fig. 3d), where the cli- 


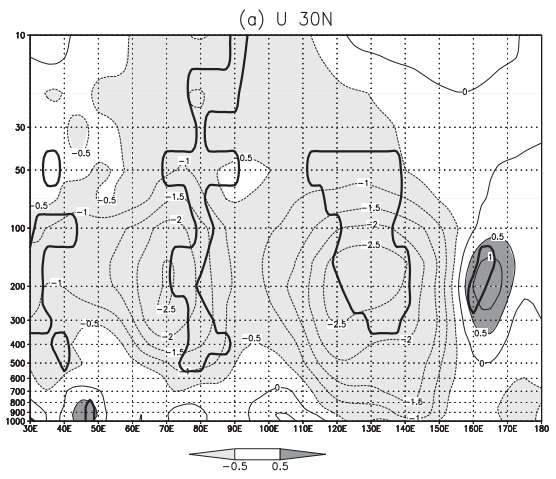

(c) $Z 100$

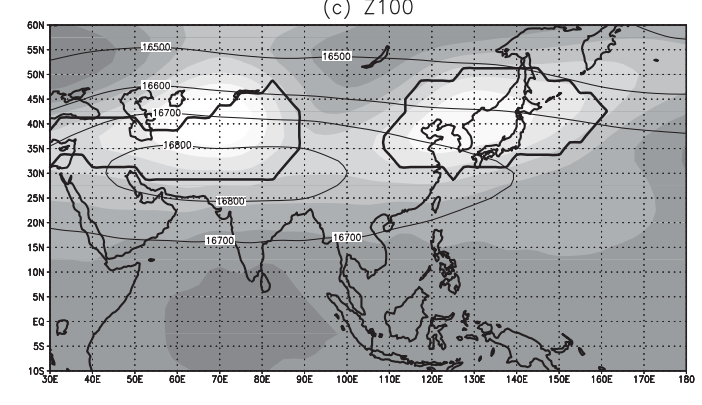

$\begin{array}{llllllllllllll}-30 & -25 & -20 & -15 & -10 & -5 & 0 & 5 & 10 & \frac{1}{15} & \frac{1}{20} & \frac{1}{25} & \frac{1}{30}\end{array}$

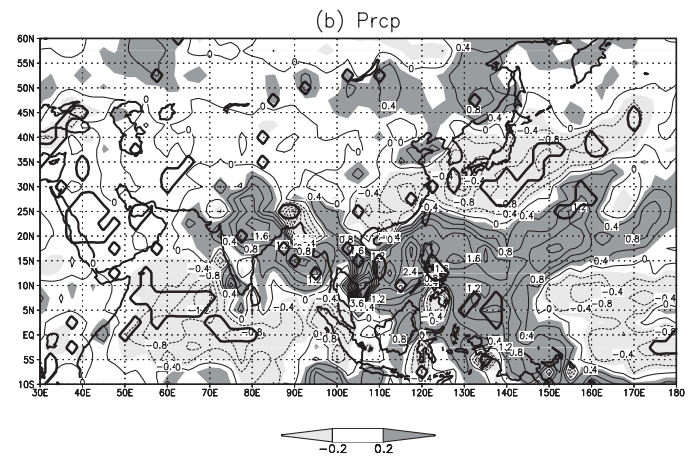

(d) omega500
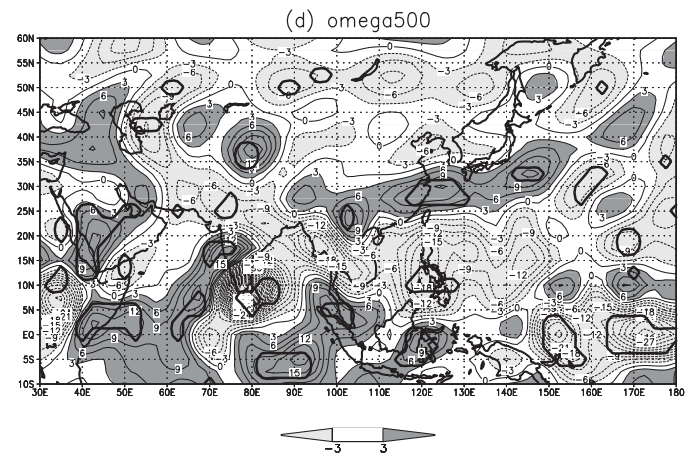

Fig. 3. (a) Longitude-pressure cross-section of zonal wind anomalies at $30^{\circ} \mathrm{N}$ in June-August in strong monsoon years. The unit is $\mathrm{m} \mathrm{s}^{-1}$. Composite maps of (b) precipitation anomalies, (c) geopotential height anomalies at $100 \mathrm{hPa}$ (shade) and mean values (thin lines) and (d) vertical p-velocity anomalies at $500 \mathrm{hPa}$ in June-August in strong monsoon years. The units are (b) $\mathrm{mm} \mathrm{day}^{-1}$, (c) $\mathrm{m}$ and (d) $10^{-3} \mathrm{~Pa} \mathrm{~s}^{-1}$. Thick lines in all panels indicate the border of the regions reaching the $95 \%$ significance level.

matological field is positive (i.e., descent). This means that the descent near the Aral Sea does not intensify in strong monsoon years, as will be shown later.

In the geopotential height distribution at $100 \mathrm{hPa}$ (Fig. 3c), significant positive anomalies are found over northeast China to Japan and over northern India to the Mediterranean in strong monsoon years. The same bimodal high pressure anomalies can also be seen at $200 \mathrm{hPa}$ in the upper troposphere (not shown). In contrast, Zhang et al. (2002) showed the existence of bimodality in the longitude of the South Asia High in northern summer. Statistical inspection of the South Asian High by Zhang et al. (2002) reveals the Tibetan mode (near $90^{\circ} \mathrm{E}$ ) and Iranian mode (near $60^{\circ} \mathrm{E}$ ). The results by Zhang et al. (2002) for the climatological field and our findings for anomaly fields (Fig. 3c) suggest that the high pressure over Iran is enhanced in strong monsoon years, whereas the high pressure over the Tibetan Plateau does not strengthen; instead, positive anomalies develop over Japan. Based on the climatological thermodynamic budget, Zhang et al. (2002) further discussed that the Iranian mode is more associated with adiabatic heating in the free atmosphere associated with descent near the Aral Sea (Fig. 2b), as well as diabatic heating near the surface. The heat budget in the anomaly field will be discussed in Subsection 4.4.

We also investigated the distribution of geopotential height anomaly at $100 \mathrm{hPa}$ in weak monsoon years (not shown). In contrast to strong monsoon years, apparent low pressure anomalies can be seen over East Asia and over West Asia. This result suggests that the effects of strong and weak monsoons are characterized by opposite responses to stratospheric circulation. Hereafter, we focus on the structure of the two high pressure anomalies over Japan and over Iran in strong monsoon years. 

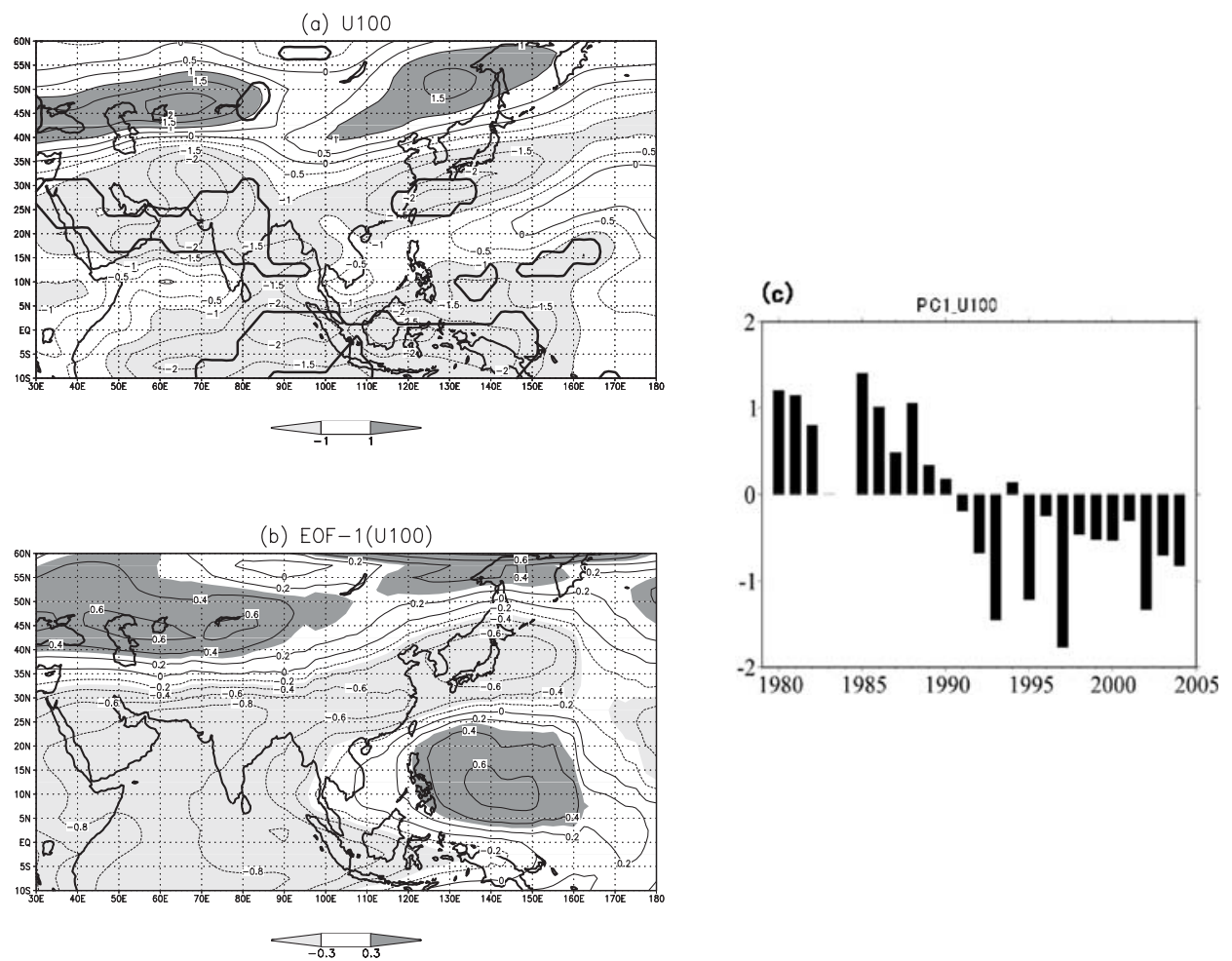

Fig. 4. (a) Composite map of zonal wind anomalies at $100 \mathrm{hPa}$ in June-August in strong monsoon years. The unit is $\mathrm{m} \mathrm{s}^{-1}$. Thick lines indicate the border of the regions reaching the $95 \%$ significance level. (b) Horizontal pattern and (c) time coefficient of the first EOF of zonal wind anomalies at $100 \mathrm{hPa}$ in JuneAugust for $1980-2004$ over Asia and north part of Eurasia $\left(30^{\circ}-180^{\circ} \mathrm{E}, 10^{\circ} \mathrm{S}-60^{\circ} \mathrm{N}\right)$.

\subsection{EOF analysis for the $100 \mathrm{hPa}$ field}

This subsection describes the EOF analysis conducted for zonal and meridional wind anomalies at $100 \mathrm{hPa}$ to extract the dominant changing mode with intensification of the monsoon. First, using zonal wind anomalies at $100 \mathrm{hPa}$, the EOF was calculated over the region of $30^{\circ}-180^{\circ} \mathrm{E}, 10^{\circ} \mathrm{S}-60^{\circ} \mathrm{N}$, in June-August from 1980 to 2004. Figure 4a indicates zonal wind anomalies in strong monsoon years. Figure $4 \mathrm{~b}$ shows the horizontal pattern of the first EOF mode, which explains $26.6 \%$ of the total variance. The first mode is characterized by a meridional structure, with negative values in the south extent and positive values in the north extent; the boundary is located roughly at the latitudes along the climatological westerly jet axis in summer (Fig. 2f). This result is similar to that of Zhang et al. (2008), who made EOF for zonal wind at $200 \mathrm{hPa}$. Figure 4c shows the time coefficient of the first EOF mode. The correlation coefficient between the Monsoon Index and this time coefficient is 0.62 and reaches the $99 \%$ significance level. Fol- lowing Sato and Takahashi (2006), we used meridional wind anomaly data for clear identification of zonally propagating wavelike patterns. Note that zonally propagating wavelike patterns were not observed in geopotential height (not shown). Figure $5 \mathrm{a}$ presents meridional wind anomalies in strong monsoon years. We see a wave-like pattern at high latitudes centered at $\sim 45^{\circ} \mathrm{N}$. Figure $5 \mathrm{~b}$ shows the horizontal pattern of the first EOF mode, which explains $21.1 \%$ of the total variance. This mode reasonably agrees with the distribution of meridional wind anomalies in strong monsoon years at high latitudes $\left(35^{\circ}-60^{\circ} \mathrm{N}\right)$, but poorly agrees at low latitudes. The time coefficient indicates positive values for all strong monsoon years (Fig. 5c). However, the correlation coefficient between the Monsoon Index and the time coefficient is 0.27 and does not reach the $95 \%$ significance level. The horizontal pattern of the second EOF mode is also similar to the distribution of meridional wind anomalies at high latitudes and explains $13.3 \%$ of the total variance (not shown). As 


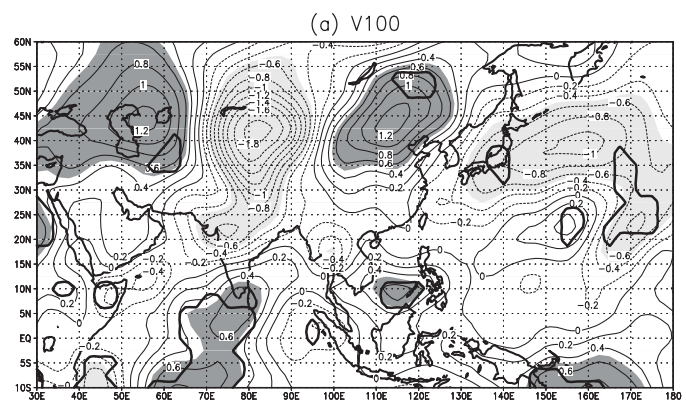

$\prod_{-0.5} \frac{1}{0.5}$
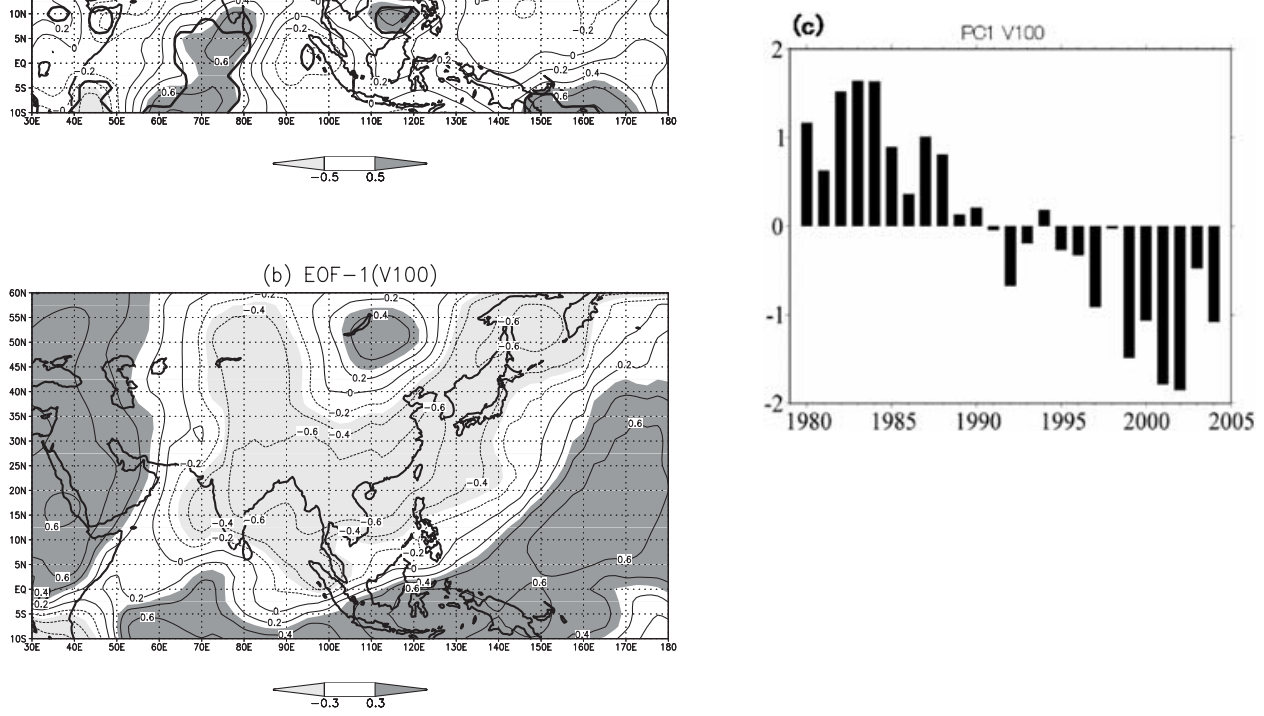

Fig. 5. (a) Composite map of meridional wind anomalies at $100 \mathrm{hPa}$ in June-August in strong monsoon years. The unit is $\mathrm{m} \mathrm{s}^{-1}$. Thick lines indicate the border of the regions reaching the $95 \%$ significance level. (b) Horizontal pattern and (c) time coefficient of the first EOF of meridional wind anomalies at $100 \mathrm{hPa}$ in June-August for $1980-2004$ over Asia and north part of Eurasia $\left(30^{\circ}-180^{\circ} \mathrm{E}, 10^{\circ} \mathrm{S}-60^{\circ} \mathrm{N}\right)$.

in the first mode, the correlation coefficient is not significant at the $95 \%$ level.

In summary, the EOF analysis for horizontal wind anomalies at $100 \mathrm{hPa}$ characterized the strong monsoon years as zonally propagating wave patterns at high latitudes. We should also note that zonal wind anomaly data is also useful to extract the characteristic varying patterns associated with the monsoon strength.

\subsection{Vorticity budget analysis at $100 \mathrm{hPa}$}

As mentioned above, significant circulation anomalies in the troposphere through the stratosphere are evident over East Asia and over Central Asia with the strength of the monsoon. In this section, we investigate the vorticity field. In the climatological field at $100 \mathrm{hPa}$, anticyclonic circulation is seen over the region of $20^{\circ}-140^{\circ} \mathrm{E}$, centered at the Tibetan Plateau (not shown). Figure 6a shows the vorticity anomalies at $100 \mathrm{hPa}$ in strong monsoon years. Negative anomalies are found over East Asia and over Central Asia. To investigate the cause of these two anticyclonic anomalies, a vorticity budget analysis was performed at 100 and $200 \mathrm{hPa}$. Here we focus on the result for $100 \mathrm{hPa}$. The vorticity equation used here is written as

$$
\begin{aligned}
\frac{\partial \zeta^{\prime}}{\partial t}= & -\left[(f+\zeta)\left(\frac{\partial u}{\partial x}+\frac{\partial v}{\partial y}\right)\right]^{\prime} \\
& -\left[\overline{\mathbf{u}} \cdot \nabla \zeta^{\prime}+\mathbf{u}^{\prime} \cdot \nabla \bar{\zeta}+(\text { nonlinear terms })\right] \\
& -v^{\prime} \frac{d f}{d y}
\end{aligned}
$$

where $\zeta$ is relative vorticity, $\mathbf{u}=(u, v)$ is horizontal wind vector, and $f$ is the Coriolis parameter. In this equation, the bar represents the 25 -year mean component (climatology), whereas the prime represents the anomaly component calculated using 6hourly data for strong monsoon years.

All terms of this equation were calculated separately. The local time change term was found to be negligible. The first linear term, $-\overline{\mathbf{u}} \cdot \nabla \zeta^{\prime}$, is the most dominant among the three horizontal advec- 
(a) vor 100

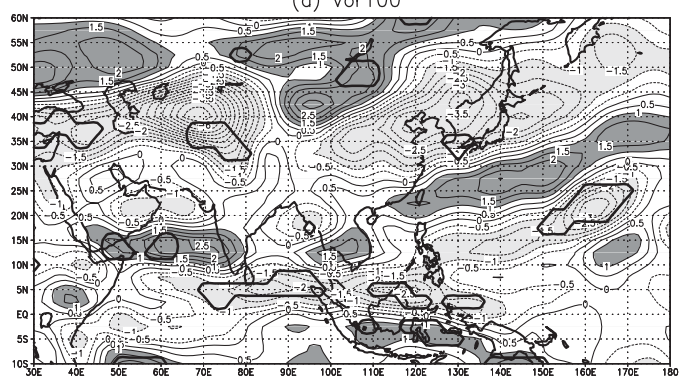

$\prod_{-1}^{1}$

(b) stretching 100

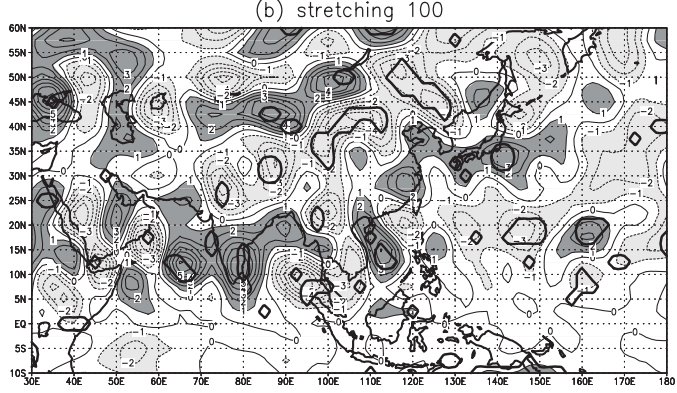

$\overbrace{-1}^{-1}$ (c) horizontal advection 100

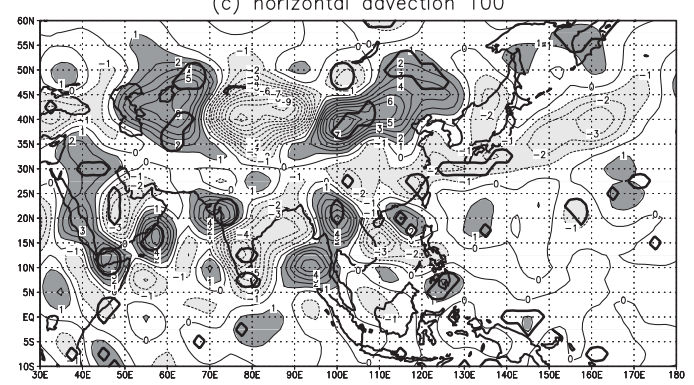

$\sum_{-1}$

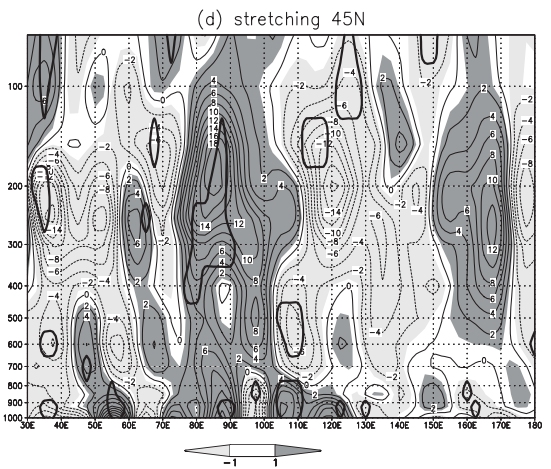

Fig. 6. (a) Composite map of vorticity anomalies at $100 \mathrm{hPa}$ in June-August in strong monsoon years. The unit is $10^{-6} \mathrm{~s}^{-1}$. Composite maps of (b) stretching term, $-\left[(f+\zeta)\left(\frac{\partial u}{\partial x}+\frac{\partial v}{\partial y}\right)\right]^{\prime}$ and (c) the first linear term of horizontal advection, $-\overline{\mathbf{u}} \cdot \nabla \zeta^{\prime}$ in the vorticity equation at $100 \mathrm{hPa}$ in June-August in strong monsoon years. (d) Longitude-pressure cross-section of stretching term in the vorticity equation at $45^{\circ} \mathrm{N}$ in June-August in strong monsoon years. The unit is $10^{-11} \mathrm{~s}^{-2}$. Thick lines in all panels indicate the border of the regions reaching the $95 \%$ significance level.

tion terms. The last term of the right-hand side is the so-called beta term, which represents the meridional advection of planetary vorticity. Though the beta term is negligible in most regions, it is important moderately at mid-latitudes. Therefore we only show the stretching term, $-\left[(f+\zeta)\left(\frac{\partial u}{\partial x}+\frac{\partial v}{\partial y}\right)\right]^{\prime}$, and the first linear term of horizontal advection in Fig. 6. Note that in the climatological field, westerly winds prevail at mid-latitudes (not shown).

Over the region from Mongolia to north China, the horizontal advection term is positive (Fig. 6c), and the stretching term is negative (Fig. 6b) and the beta term is weakly negative (not shown). Such a vorticity balance is associated with the formation of significant high pressure anomalies over Japan (Fig. 3c). Over the south of Japan the peaks of these terms are shifted eastward from the center of the high pressure anomaly by a quarter wavelength. This can be explained by the fact that the longitudinal gradient of vorticity anomaly is posi- tive $\left(\frac{\partial \zeta^{\prime}}{\partial x}>0\right)$ over the south of Japan (not shown).

Zonal distributions of the stretching term and horizontal advection term at $100 \mathrm{hPa}$ over Japan are consistent with those of descent anomalies at $500 \mathrm{hPa}$ (Fig. 3d). It is concluded that both the stretching term and the horizontal advection term are greater than the beta term in the vorticity budget of the high pressure anomaly over Japan.

Next, the vorticity budget over Central Asia is investigated. The connection between the stretching term and the high pressure anomaly near Iran was found to be obscure, unlike in East Asia. The horizontal advection term is more important near Iran at $100 \mathrm{hPa}$. However, the stretching term and the beta term are not negligible. It should be noted that all the above descriptions about the vorticity budget can basically be applied to the $200-\mathrm{hPa}$ field as well.

Figure 6d shows the longitude-pressure crosssection of the stretching term at $45^{\circ} \mathrm{N}$. There are 
(a) potential temperature 100

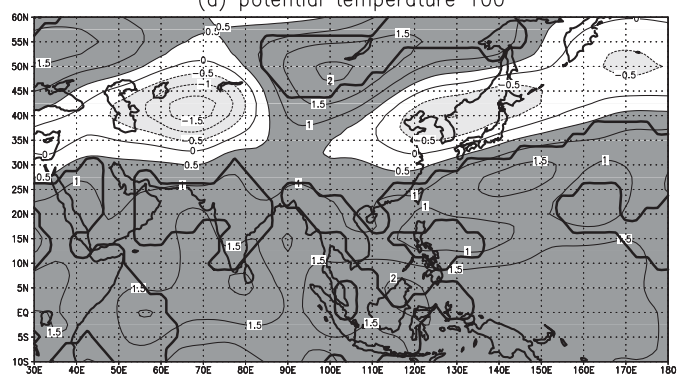

$\frac{1}{-0.5}_{0.5}$

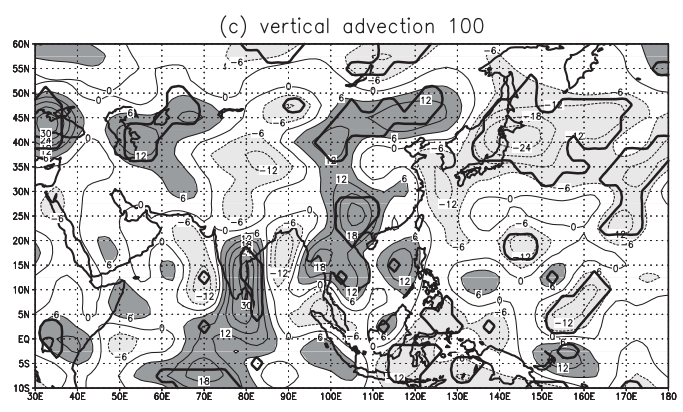

$\prod_{-6}^{1} \frac{1}{6}$ (b) horizontal advection 100

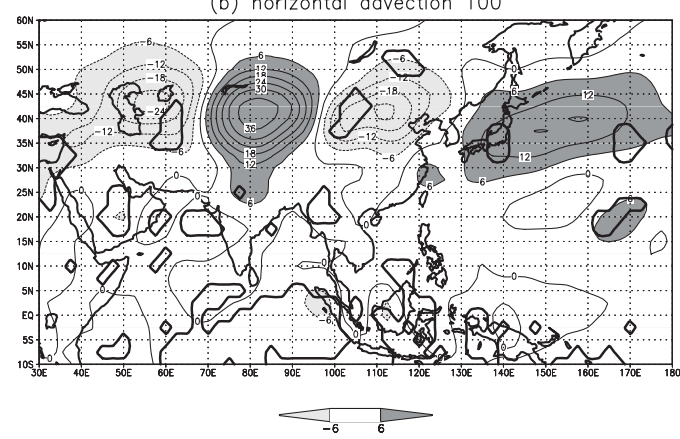

(d) Q 100

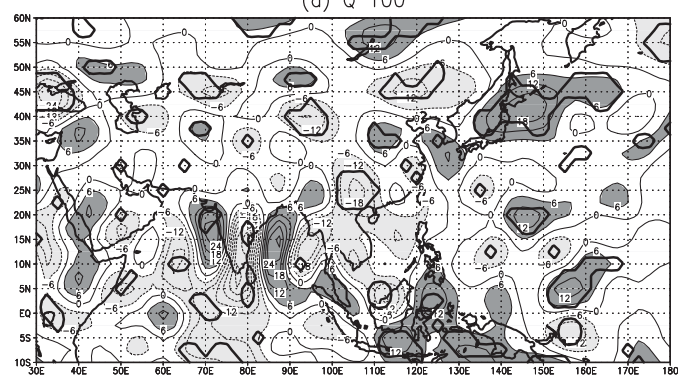

$\frac{1}{-6} \frac{1}{6}$

Fig. 7. (a) Composite map of potential temperature anomalies at $100 \mathrm{hPa}$ in June-August in strong monsoon years. The unit is $\mathrm{K}$. Composite maps of (b) the second linear term of horizontal advection, $-\mathbf{u}^{\prime} \cdot \nabla \bar{\theta}$, (c) the second linear term of vertical advection, $-\omega^{\prime} \frac{\partial \bar{\theta}}{\partial p}$ and (d) diabatic heating term $Q^{\prime}$ in the thermodynamic equation at $100 \mathrm{hPa}$ in June-August in strong monsoon years. The unit is $10^{-6} \mathrm{~K} \mathrm{~s}^{-1}$. Thick lines in all panels indicate the border of the regions reaching the $95 \%$ significance level.

apparent negative values over Mongolia from 400 to $70 \mathrm{hPa}$ and positive values near the Tian Shan range from 700 to $70 \mathrm{hPa}$. These anomalies are centered around the tropopause. In addition, the horizontal advection term is approximately balanced with the stretching term for both anomalies (not shown). The vertically elongated negative forcing over East Asia may indicate the possibility of stratosphere-troposphere coupling, as will be discussed in Subsections 4.5 and 4.8.

\subsection{Heat budget analysis at $100 \mathrm{hPa}$}

The heat budget at $100 \mathrm{hPa}$ is calculated to examine the thermal characteristics of the high pressure anomalies over Japan and over Iran. The thermodynamic equation used here is written as

$$
\begin{aligned}
\frac{\partial \theta^{\prime}}{\partial t}= & -\left[\overline{\mathbf{u}} \cdot \nabla \theta^{\prime}+\mathbf{u}^{\prime} \cdot \nabla \bar{\theta}+(\text { nonlinear terms })\right] \\
& -\left[\bar{\omega} \frac{\partial \theta^{\prime}}{\partial p}+\omega^{\prime} \frac{\partial \bar{\theta}}{\partial p}+(\text { nonlinear terms })\right]+Q^{\prime},
\end{aligned}
$$

where $\theta$ is potential temperature, $\omega$ is vertical pvelocity, and $Q$ is diabatic heating. $Q$ is calculated as a residual in this thermodynamic equation.

As for the climatological field at $100 \mathrm{hPa}$, the meridional gradient of potential temperature is positive $\left(\frac{\partial \bar{\theta}}{\partial y}>0\right)$, unlike in the troposphere (not shown). Figure 7 a shows the distribution of potential temperature anomalies at $100 \mathrm{hPa}$ in strong monsoon years. There are negative temperature anomalies near Japan and near the Aral Sea, and apparent positive temperature anomalies in other regions. All terms in the thermodynamic equation were calculated separately. The local time change term was found to be negligible. Figures $7 b, 7 c$, and $7 \mathrm{~d}$ show horizontal advection of climatological temperature by anomaly horizontal winds, vertical advection of climatological temperature by anomaly vertical winds, and diabatic heating, respectively. Firstly, the vertical advection term is focused. At $100 \mathrm{hPa}$, potential temperature increases with height $\left(\frac{\partial \bar{\theta}}{\partial p}<0\right)$. Thus, in the regions where as- 
cent occurs $\left(\omega^{\prime}<0\right)$, the vertical advection term becomes negative $\left(-\omega^{\prime} \frac{\partial \bar{\theta}}{\partial p}<0\right)$. In other words, negative potential temperature anomalies $\left(\theta^{\prime}<0\right)$ are related to the cooling due to adiabatic ascent. Thus, negative values of the vertical advection term over Japan shown in Fig. 7c are associated with negative potential temperature anomalies (Fig. 7a). The second linear term of horizontal advection and the diabatic heating term are positive so as to balance with the second linear term of vertical advection over Japan (Figs. $7 \mathrm{~b}$ and $7 \mathrm{~d}$ ). Furthermore, $-v^{\prime} \frac{\partial \bar{\theta}}{\partial y}$ was found to be much greater than $-u^{\prime} \frac{\partial \bar{\theta}}{\partial x}$ (Note that over Japan, $v^{\prime}<0$ in Fig 5a and $\frac{\partial \bar{\theta}}{\partial y}>0$ at $100 \mathrm{hPa}$ ). The thermal balance described above is connected with the formation of negative potential temperature anomalies over Japan (Fig. 7a).

In contrast, the negative temperature anomalies near the Aral Sea are associated with negative values of the horizontal advection term. The vertical advection term is positive so as to balance with the horizontal advection term. Zhang et al. (2002) showed that, in addition to diabatic heating near the surface, adiabatic heating with descent near the Iranian Plateau is dominant in forming the high pressure in the climatological field. In our analysis, we found that this descent tends to be enhanced in strong monsoon years. As discussed in Subsection 4.1, this intensification is also observable in the middle troposphere. However, for the negative temperature anomalies over Iran, the horizontal advection term has a greater contribution (Figs. 7a and $7 \mathrm{~b}$ ). Thus, the negative potential temperature anomalies over Japan and over the Aral Sea have different structures in the thermal budget.

\subsection{Wave activity flux analysis}

Meridional wind anomalies at $100 \mathrm{hPa}$ in Fig. 5a suggest the existence of Rossby waves. To estimate the three-dimensional (3D) propagation of quasistationary Rossby waves quantitatively, we calculate the wave activity flux formulated by Takaya and Nakamura (2001) at 100, 500, and $850 \mathrm{hPa}$ in strong monsoon years. The wave activity flux $\mathbf{W}$ is written as

$$
\mathbf{W}=\frac{p}{2|\overline{\mathbf{u}}|}\left(\begin{array}{c}
\bar{u}\left(\psi_{x}^{\prime 2}-\psi^{\prime} \psi_{x x}^{\prime}\right)+\bar{v}\left(\psi_{x}^{\prime} \psi_{y}^{\prime}-\psi^{\prime} \psi_{x y}^{\prime}\right) \\
\bar{u}\left(\psi_{x}^{\prime} \psi_{y}^{\prime}-\psi^{\prime} \psi_{x y}^{\prime}\right)+\bar{v}\left(\psi_{y}^{\prime 2}-\psi^{\prime} \psi_{y y}^{\prime}\right) \\
\varepsilon\left[\bar{u}\left(\psi_{x}^{\prime} \psi_{z}^{\prime}-\psi^{\prime} \psi_{x z}^{\prime}\right)+\bar{v}\left(\psi_{y}^{\prime} \psi_{z}^{\prime}-\psi^{\prime} \psi_{y z}^{\prime}\right)\right]
\end{array}\right),
$$

where $\overline{\mathbf{u}}=(\bar{u}, \bar{v})$ is horizontal wind vector in the climatological field, $p=($ pressure $/ 1000 \mathrm{hPa})$ is the normalized pressure, and $\psi^{\prime}$ is stream function anomaly. This flux is independent of wave phases and parallel to the group-velocity in zonally varying basic flow.

Figure 8 shows the distribution of wave activity flux at 100,500 , and $850 \mathrm{hPa}$ in June-August in strong monsoon years. Wave divergences are apparent over the Aral Sea and over Mongolia at $100 \mathrm{hPa}$ (Fig. 8a). At $500 \mathrm{hPa}$, northward fluxes are dominant over the region from the South China Sea to south of Japan (Fig. 8b). Furthermore, northward fluxes over the Philippines are more striking at $850 \mathrm{hPa}$ (Fig. 8c). The northward fluxes over the Philippines correspond to the process that a stationary Rossby wave generated over the Philippines forms the high pressure over Japan, as described by Nitta (1987). In other words, the convergence of wave activity fluxes over Japan seems to be associated with inactive Baiu front in strong monsoon years which can be seen in Fig. 3b. Southeastward fluxes are also found over the region from Mongolia to Japan at 100 and $500 \mathrm{hPa}$.

Next, we focus on the circulation anomalies near Iran. Much precipitation in India might be associated with the high pressure anomalies near Iran; however, northward fluxes are not apparent near India in the lower troposphere (Figs. 8b and 8c). Precipitation in India and the pressure field at $100 \mathrm{hPa}$ over Iran are not significantly correlated, as described later. This suggests that the pressure anomalies over Iran are different in maintenance mechanism from those over Japan.

Figure $8 d$ shows the longitude-pressure crosssection of wave activity flux at $45^{\circ} \mathrm{N}$. We see that upward fluxes occur in the middle troposphere to the tropopause over the Aral Sea and over Mongolia, with wave divergences. Upward fluxes generally represent northward heat transport. We see that the two upward flux regions are collocated with the two significant high pressure anomalies in the lower stratosphere. Upward fluxes over Mongolia reach the stratosphere; this is consistent with the negative stretching term at $100 \mathrm{hPa}$ (Figs. 6b and 6d). In contrast, upward fluxes over the Aral Sea are not apparent in the lower stratosphere; this is consistent with the obscure stretching effect at $100 \mathrm{hPa}$. Precipitation in northern India and in the Philippines (Fig. 3b) seems to correspond to wave divergences at $100 \mathrm{hPa}$ over the Aral Sea and over Mongolia, respectively (Fig. 8a).

The vorticity and heat budget analyses revealed that the structure of high pressure anomalies over 
(a) WAF,Z 100

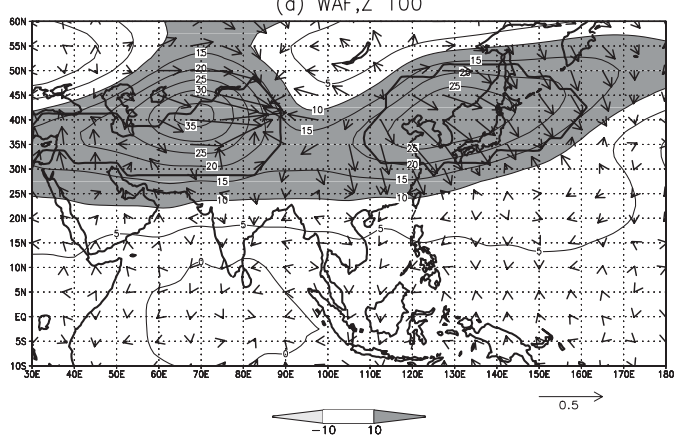

(c) WAF,Z 850

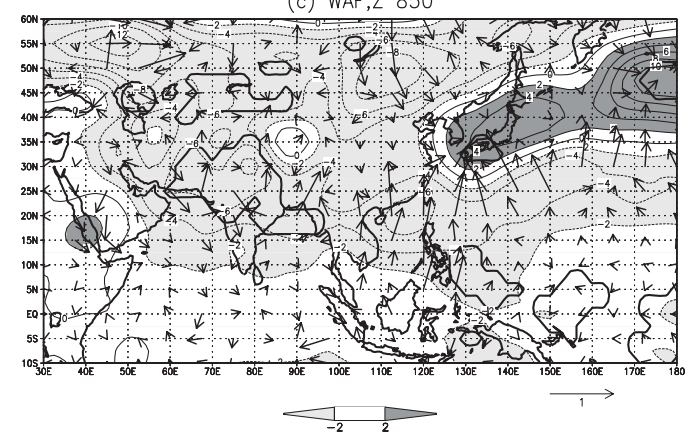

(b) WAF,Z 500

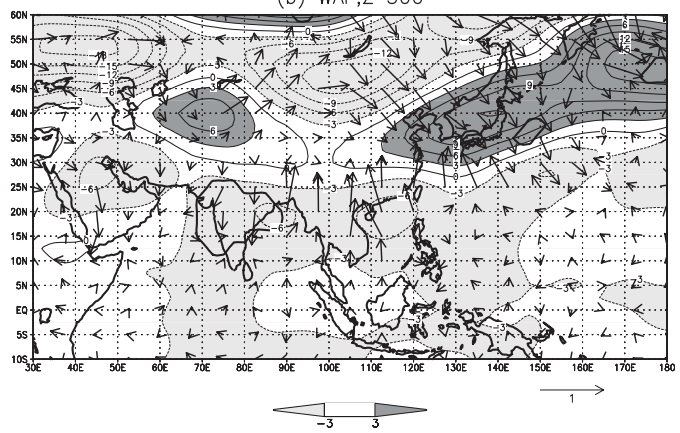

(d) WAF,Z $45 \mathrm{~N}$

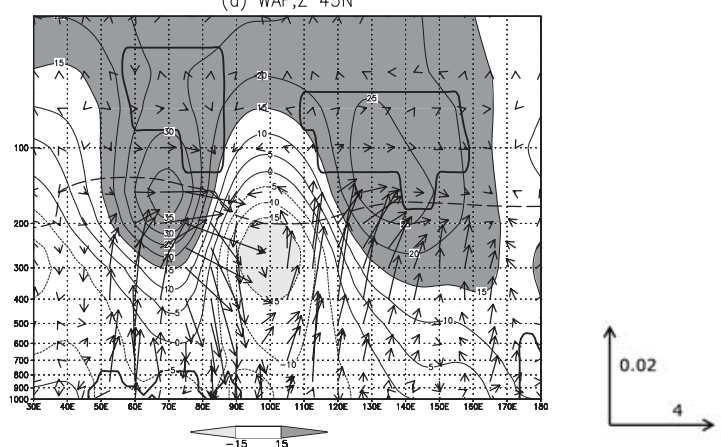

Fig. 8. Wave activity flux and geopotential height anomalies at (a) $100 \mathrm{hPa}$, (b) $500 \mathrm{hPa}$, and (c) $850 \mathrm{hPa}$ in June-August in strong monsoon years. (d) Longitude-pressure cross-section of wave activity flux and geopotential height anomalies at $45^{\circ} \mathrm{N}$ in June-August in strong monsoon years. The dashed line shows the tropopause. The units are $\mathrm{m}^{2} \mathrm{~s}^{-2}$ for wave activity flux and $\mathrm{m}$ for geopotential height. Thick lines in all panels indicate the border of the regions reaching the $95 \%$ significance level on geopotential height.

East Asia differs from those over Central Asia. The difference may be caused by the difference in precipitation over northern India and over the Philippines or in the wave propagation processes at midlatitudes. To confirm this, the connection between the Asian summer monsoon and the meridional circulation in East Asia and in Central Asia is investigated in following subsections.

\subsection{Connection between the Asian monsoon and the meridional circulation in East Asia and in Central Asia}

This subsection examines the meridional circulation and the stretching term in vorticity equation to investigate the association between precipitation in the Philippines and India and high pressure fields at $100 \mathrm{hPa}$ over Japan and Iran. Figures 9a-d show quasi-meridional circulation and the stretching term over Central Asia and over East Asia shown as the area A and B in Fig. 9e, respectively.
Because horizontal divergence is mainly caused by ageostrophic flow, ageostrophic components of horizontal wind were used for the circulation. Here, ageostrophic winds are defined as the deviation from the geostrophic winds calculated from the distribution of geopotential height.

At first, meridional circulation in Central Asia is focused. Figures $9 \mathrm{a}$ and $9 \mathrm{c}$, respectively, present the cross-sections of horizontal-vertical wind and stretching term in the climatological and anomaly fields over Central Asia (area A in Fig. 9e). Ascent over India (near $20^{\circ} \mathrm{N}$ ) and descent over the Kyzylkum Desert southeast of the Aral Sea (near $40^{\circ} \mathrm{N}$ ) are clearly shown in Central Asia (Fig. 9a). This climatological meridional circulation does not seem to conflict with the result of Rodwell and Hoskins (1996). However, ascent anomalies are seen over India and over the Aral Sea (Fig. 9c). In other words, ascent over India intensifies, whereas descent over the Aral Sea weakens in strong monsoon 

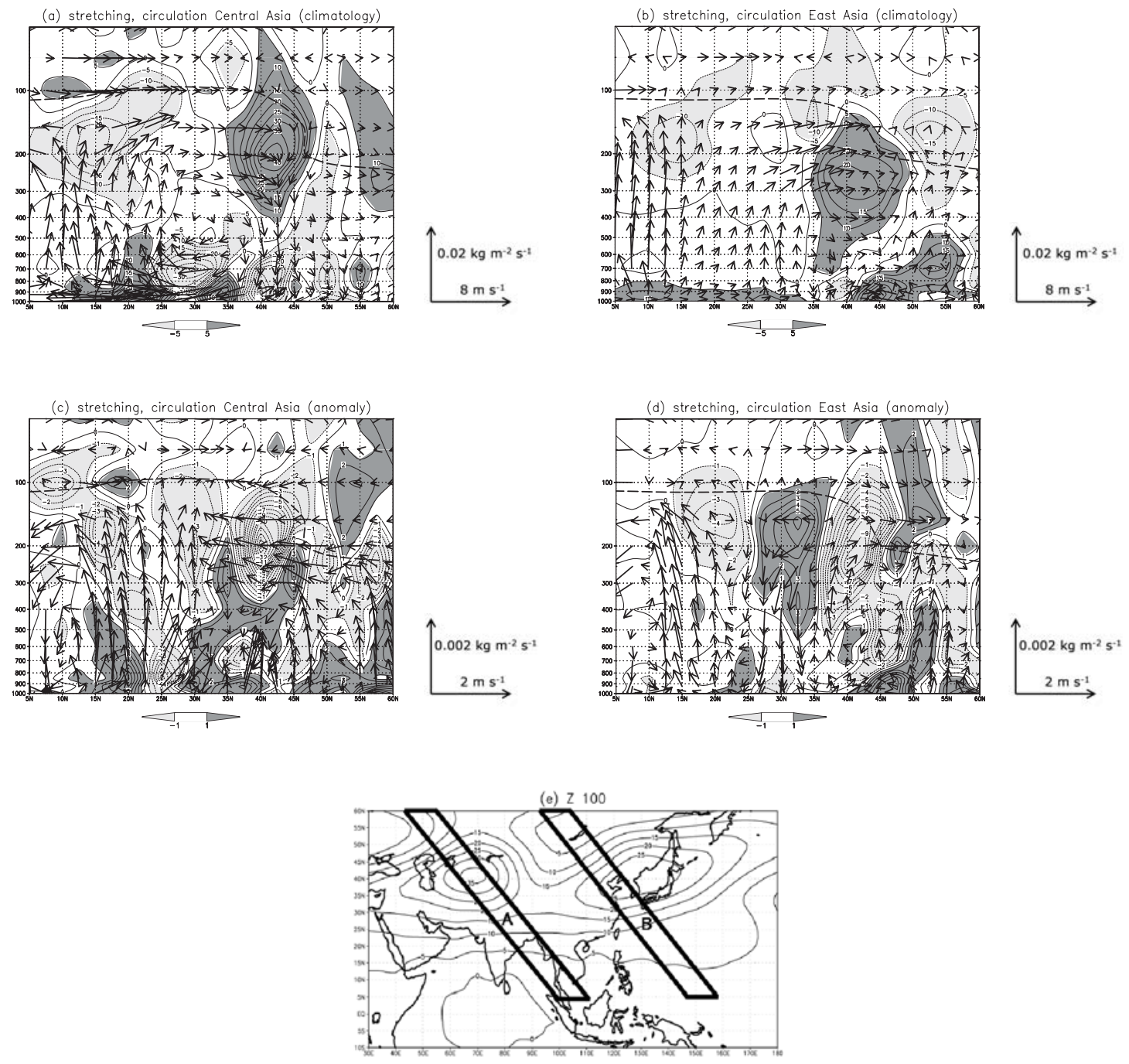

Fig. 9. Cross-sections of (a) climatological and (c) anomaly fields for horizontal-vertical wind and stretching term in vorticity equation averaged in Central Asia (A in Fig. 9e) in June-August in strong monsoon years. Cross-sections of (b) climatological and (b) anomaly fields for horizontal-vertical wind and stretching term in vorticity equation averaged in East Asia (B in Fig. 9e) in June-August in strong monsoon years. The dashed lines in panels (a)-(d) show the tropopause. The unit of stretching term is $10^{-11} \mathrm{~s}^{-2}$.

years. Negative stretching anomalies are seen both over India and over the Aral Sea in connection with these ascent anomalies, which correspond to the significant negative pressure anomalies over both areas in the lower troposphere (Fig. 8c).

Figures $9 \mathrm{~b}$ and $9 \mathrm{~d}$ show cross-sections over East Asia (area B in Fig. 9e). Ascent east of the Philippines with much precipitation and ascent over the region from the south of Japan through the Yellow Sea are evident in the climatological field (Fig. 9b). In the anomaly field, ascent anomalies occur east of the Philippines with much precipitation and over Mongolia with a negative stretching term; subsequent descent anomalies occur at $\sim 30^{\circ} \mathrm{N}$. Consequently, in strong monsoon years there seems to exist a "unified" circulation which is a continuous flow from the upper troposphere near Mongolia through the upper troposphere over the Philippines (Fig. 9d). Negative stretching anomalies are observed over both the Philippines and Mongolia from the middle troposphere to the lower stratosphere. However, negative anomalies over the Phil- 
(a) $\operatorname{cor}[\operatorname{Prcp}(75-90 \mathrm{E}, 15-35 \mathrm{~N})$, vor $100 \mathrm{hPa}]$

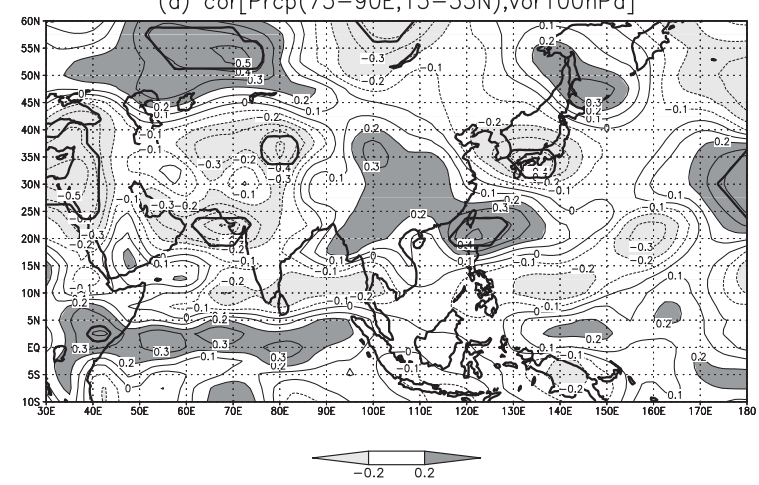

(b) $\operatorname{cor}[\operatorname{Prcp}(105-140 \mathrm{E}, 0-20 \mathrm{~N})$, vor100hPa]

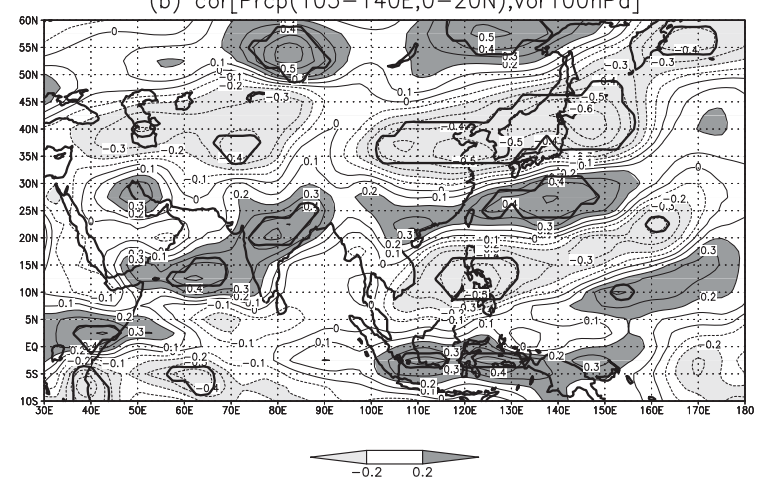

Fig. 10. Distributions of correlation coefficient between precipitation over (a) northern India $\left(75^{\circ}-90^{\circ} \mathrm{E}\right.$, $\left.15^{\circ}-35^{\circ} \mathrm{N}\right)$ and $(\mathrm{b})$ the Philippines $\left(105^{\circ}-140^{\circ} \mathrm{E}, 0^{\circ}-20^{\circ} \mathrm{N}\right)$ and vorticity at $100 \mathrm{hPa}$ in June-August for 1980-2004. Thick lines indicate the border of the regions reaching the $95 \%$ significance level.

ippines are not predominant compared to those over Mongolia. According to detailed analysis of the stretching term, we found that $-\left[f\left(\frac{\partial u}{\partial x}+\frac{\partial v}{\partial y}\right)\right]^{\prime}$ is more dominant than $-\left[\zeta\left(\frac{\partial u}{\partial x}+\frac{\partial v}{\partial y}\right)\right]^{\prime}$ over Mongolia, while negative forcing is due to $-\left[\zeta\left(\frac{\partial u}{\partial x}+\frac{\partial v}{\partial y}\right)\right]^{\prime}$ over the Philippines (not shown). This result means that planetary vorticity $f$ and relative vorticity $\zeta$ are responsible for the remarkable difference in negative forcing anomalies between low and middle latitudes. These results indicate that the high pressure anomalies in the lower stratosphere are associated with the meridional circulation anomalies at the low to middle latitudes in the troposphere. It should be noted that the vorticity budget analysis in Subsection 4.3 indicated that the high pressure anomalies form not over Mongolia but over Japan; this is due to the eastward advection.

\subsection{Correlation coefficient between the high pressure anomalies in the lower stratosphere and precipitation at low latitudes}

Figures 10a and 10b show the distributions of correlation coefficient between precipitation in two regions (i.e., over northern India $\left(75^{\circ}-90^{\circ} \mathrm{E}, 15^{\circ}-\right.$ $\left.35^{\circ} \mathrm{N}\right)$ and over the Philippines $\left(105^{\circ}-140^{\circ} \mathrm{E}, 0^{\circ}-\right.$ $\left.20^{\circ} \mathrm{N}\right)$ ) and vorticity at $100 \mathrm{hPa}$ in June-August for 1980-2004, respectively. There are significant correlations between precipitation over the Philippines and the circulation field over Japan (Fig. 10b). Precipitation in India and vorticity south of the Tian Shan range (near $80^{\circ} \mathrm{E}, 35^{\circ} \mathrm{N}$ ) are also significantly correlated (Fig. 10a). However, significant areas for Central Asia are much smaller than those for East Asia. This suggests that the connec- tion between precipitation at low latitudes and the circulation field at mid-latitudes is more significant in East Asia than in Central Asia. The connection in East Asia can be also inferred from the wave activity flux analysis in Subsection 4.5 and the energy budget analysis in Subsection 4.8. Ascent anomalies over Mongolia are associated with the negative stretching term in the lower stratosphere (Figs. 6b and 9d), and the climatological westerlies advect these negative anomalies eastward (Fig. 6c). Consequently, the high pressure anomalies form over Japan in the lower stratosphere. Pressure anomalies in the lower stratosphere over Japan seem to be strongly connected to convections over the Philippines through wave activity fluxes. However, the connection in Central Asia is obscure because of the lack of northward wave fluxes in India where there exist active convections. The formation process of the high pressure anomalies over Central Asia will be discussed from the viewpoint of the energetics in the next subsection. We can obtain similar results for East Asia using diabatic heating and vertical p-velocity at $850 \mathrm{hPa}$ as substitutes for precipitation and vorticity, respectively. Vertical flows over Mongolia have significant negative correlations with diabatic heating in the Philippines (not shown). On the other hand, there are few significant areas in Central Asia with the $Q-\omega$ analysis (not shown). In summary, we found that convective activity at low latitudes is likely to be associated with the circulation fields at mid-latitudes in East Asia through vertical motions, whereas the connection between convection over northern India and the circulation fields over the Aral Sea is unclear. 


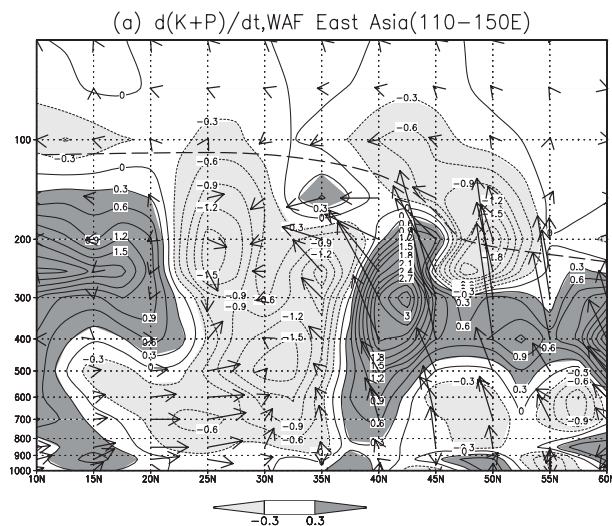

(b) baroclinicity, WAF East Asia(110-150E)

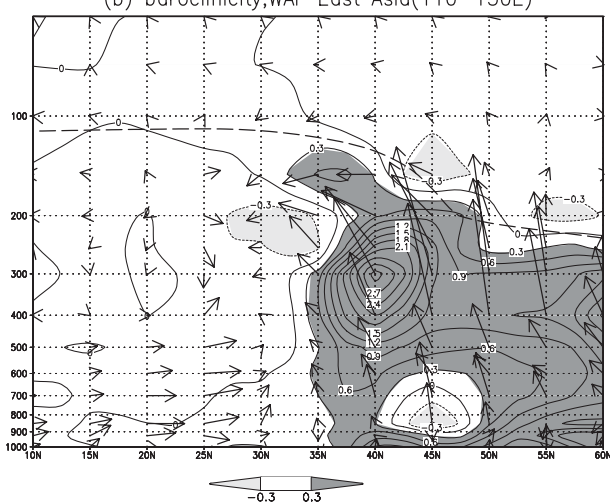

(c) generation, WAF East Asia(110-150E)
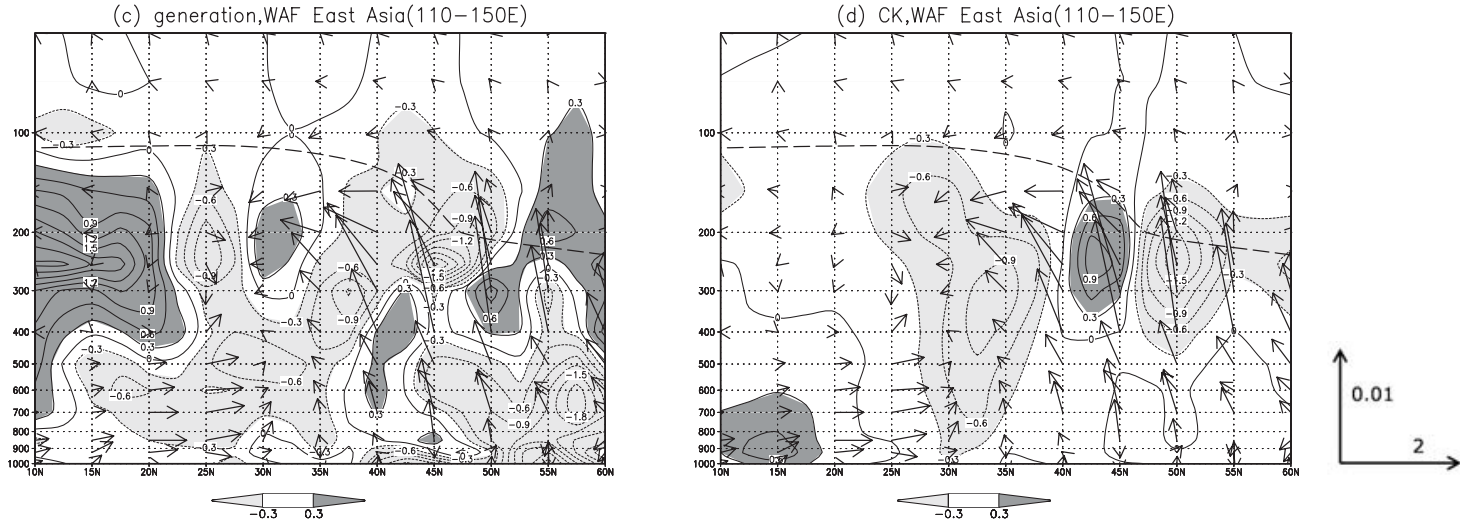

Fig. 11. Latitude-pressure cross-sections of (a) sum of the right-hand side of energy conversion equation, $\frac{v^{\prime 2}-u^{\prime 2}}{2}\left(\frac{\partial \bar{u}}{\partial x}-\frac{\partial \bar{v}}{\partial y}\right)-u^{\prime} v^{\prime}\left(\frac{\partial \bar{u}}{\partial y}+\frac{\partial \bar{v}}{\partial x}\right)-\frac{R_{d}}{p \sigma}\left(u^{\prime} T^{\prime} \frac{\partial \bar{T}}{\partial x}+v^{\prime} T^{\prime} \frac{\partial \bar{T}}{\partial y}\right)+\frac{R_{d}}{p \sigma C_{p}} Q^{\prime} T^{\prime}$ (b) baroclinicity term, $-\frac{R_{d}}{p \sigma}\left(u^{\prime} T^{\prime} \frac{\partial \bar{T}}{\partial x}+\right.$ $\left.v^{\prime} T^{\prime} \frac{\partial \bar{T}}{\partial y}\right)$ (c) generation term, $\frac{R_{d}}{p \sigma C_{p}} Q^{\prime} T^{\prime}(\mathrm{d})$ barotropic conversion term, $\frac{v^{\prime 2}-u^{\prime 2}}{2}\left(\frac{\partial \bar{u}}{\partial x}-\frac{\partial \bar{v}}{\partial y}\right)-u^{\prime} v^{\prime}\left(\frac{\partial \bar{u}}{\partial y}+\frac{\partial \bar{v}}{\partial x}\right)$ averaged over East Asia $\left(110^{\circ}-150^{\circ} \mathrm{E}\right)$ in June-August in strong monsoon years. Also shown are the wave activity fluxes. The dashed lines in all panels show the tropopause. The units are $10^{-1} \mathrm{~kg} \mathrm{~m}^{-1} \mathrm{~s}^{-3}$ for energy equation terms and $\mathrm{m}^{2} \mathrm{~s}^{-2}$ for wave activity fluxes.

\subsection{Energetics for East Asia and Central Asia}

Energy conversion is estimated for both East Asia $\left(110^{\circ}-150^{\circ} \mathrm{E}\right)$ and Central Asia $\left(50^{\circ}-90^{\circ} \mathrm{E}\right)$ in strong monsoon years. Equation for the rate of change in perturbation total energy is written as

$$
\begin{aligned}
\frac{\partial\left(K E^{\prime}+P E^{\prime}\right)}{\partial t} \approx & \frac{v^{\prime 2}-u^{\prime 2}}{2}\left(\frac{\partial \bar{u}}{\partial x}-\frac{\partial \bar{v}}{\partial y}\right) \\
& -u^{\prime} v^{\prime}\left(\frac{\partial \bar{u}}{\partial y}+\frac{\partial \bar{v}}{\partial x}\right) \\
& -\frac{R_{d}}{p \sigma}\left(u^{\prime} T^{\prime} \frac{\partial \bar{T}}{\partial x}+v^{\prime} T^{\prime} \frac{\partial \bar{T}}{\partial y}\right) \\
& +\frac{R_{d}}{p \sigma C_{p}} Q^{\prime} T^{\prime}
\end{aligned}
$$

where $K E^{\prime}$ is the perturbation kinetic energy, and $P E^{\prime}$ is the perturbation potential energy. $\sigma$ denotes the static stability, $R_{d}$ is the gas constant for dry air, and $C_{p}$ is the specific heat of dry air at constant pressure. All terms in the equation are estimated. Figures 11 and 12 show the energy conversion and the wave activity fluxes for East Asia and for Central Asia, respectively. In East Asia, barotropic energy conversion is positive in the low-latitude lower troposphere (Fig. 11d), and the generation of perturbation potential energy by convection is positive in the middle and upper troposphere (Fig. 11c). At mid-latitudes, baroclinic energy conversion is positive in the troposphere (Fig. 11b). Positive barotropic energy conversion coincides with northward fluxes at low latitudes, and positive baroclinic en- 

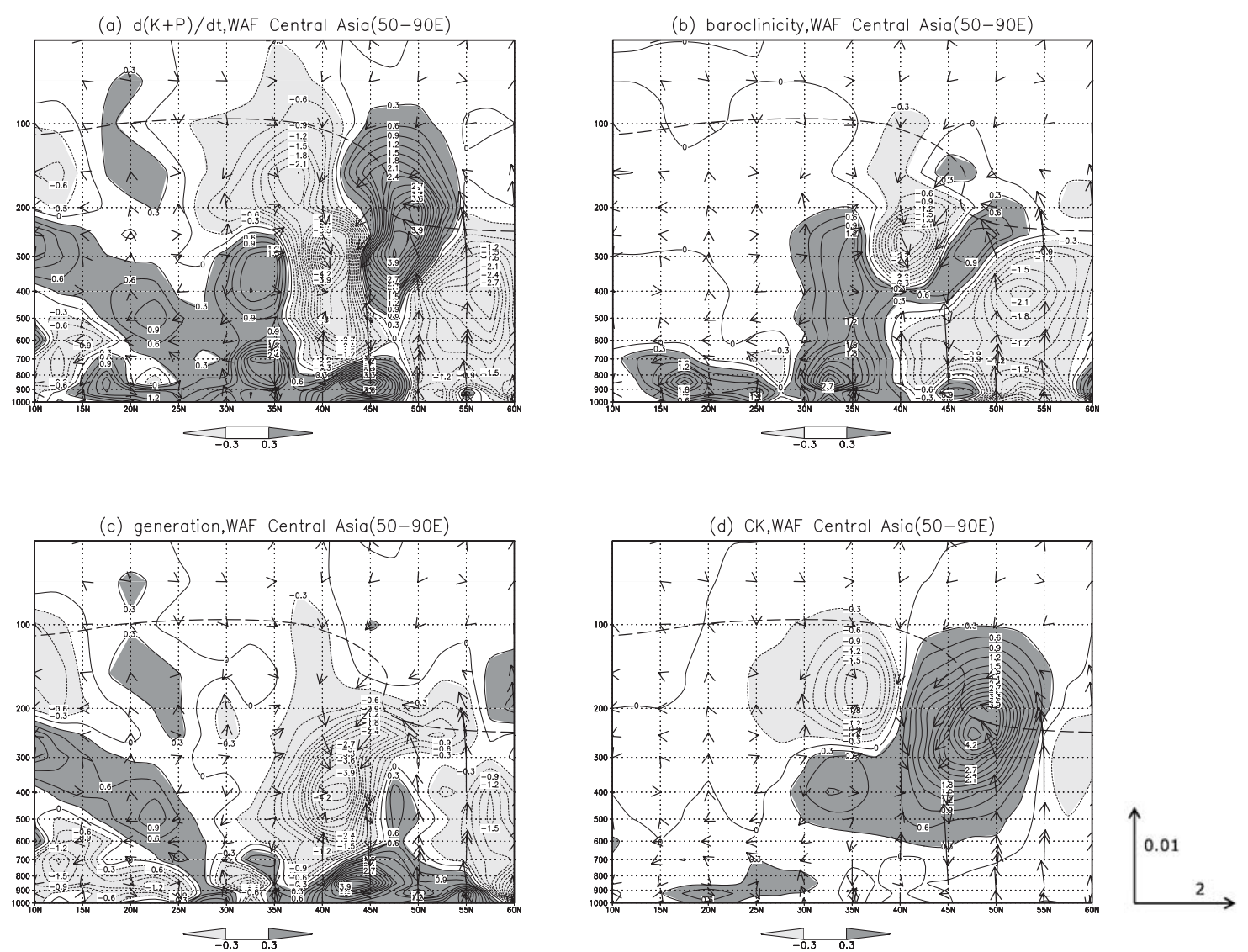

Fig. 12. As in Fig. 11, but for Central Asia $\left(50^{\circ}-90^{\circ} \mathrm{E}\right)$.

ergy conversion accords with upward fluxes at midlatitudes. Furthermore, the convergence of northward fluxes near $30^{\circ} \mathrm{N}$ is likely to be connected with the inactive Baiu front over Japan. In the energetics for Central Asia, barotropic energy conversion is more dominant than baroclinic energy conversion at mid-latitudes; and in the tropics, the generation of perturbation potential energy is positive in the middle and upper troposphere (Figs. $12 \mathrm{~b}, 12 \mathrm{c}$, and $12 \mathrm{~d}$ ). Sum of the right-hand side of energy conversion equation is also positive near $30^{\circ} \mathrm{N}$ for Central Asia, unlike for East Asia (Figs. 11a and 12a). Upward fluxes are found at midlatitudes, whereas northward fluxes are not found in the tropics despite much precipitation in India.

The total wavenumber of the stationary Rossby wave $K$ (see Section 3) is calculated for East Asia $\left(110^{\circ}-130^{\circ} \mathrm{E}\right)$ and for Central Asia $\left(50^{\circ}-70^{\circ} \mathrm{E}\right)$ to investigate the cause of the difference in energetics and in wave activity fluxes. Figure $13 \mathrm{~b}$ shows the result for East Asia. The areas where $K$ is real $\left(K^{2} \geq 0\right)$ are seen in the lower troposphere over the Philippines. This confirms that the precipitation in the Philippines is strongly connected with the high pressure anomalies over Japan through internal Rossby waves propagating northward in the lower troposphere. In contrast, Fig. 13a shows that the total wavenumber $K$ is imaginary over India in the lower troposphere. Therefore, stationary Rossby waves are more difficult to propagate over Central Asia compared to East Asia. Finally, we investigate the difference in internal dynamical processes at mid-latitudes between East Asia and Central Asia. Baroclinic energy conversion is dominant in East Asia, whereas barotropic energy conversion is dominant in Central Asia. As part of the baroclinic conversion term, longitudinal and latitudinal components of the horizontal gradient of temperature in the climatologival field are investigated. The latitudinal component for both regions is found to be almost the same. In contrast, the longitudinal component is quite different. Apparently, there are negative values in East Asia and positive values in Central Asia from the troposphere 

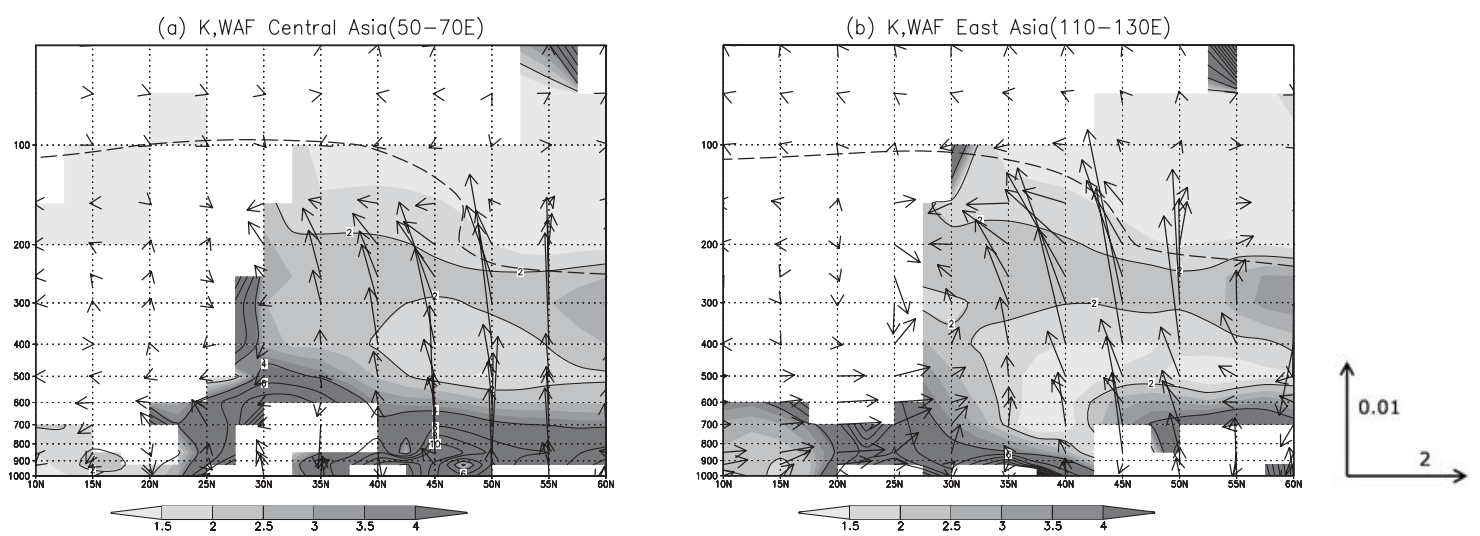

Fig. 13. Latitude-pressure cross-sections of climatological fields of the total wavenumber of stationary Rossby waves $K$ in (a) Central Asia $\left(50^{\circ}-70^{\circ} \mathrm{E}\right)$ and (b) East Asia $\left(110^{\circ}-130^{\circ} \mathrm{E}\right)$ in June-August for 1980-2004. Wave activity fluxes are shown by vectors. The dashed lines show the tropopause. The units are $10^{-6} \mathrm{~m}^{-1}$ for $K$ and $\mathrm{m}^{2} \mathrm{~s}^{-2}$ for wave activity fluxes.

through the tropopause. This difference can be caused by the difference in vertical shear of the climatological meridional wind through the thermal wind balance.

\section{Summary and discussion}

We examined how the atmospheric anomaly field over the Asian region changes with monsoon strength. In particular, we focused on the processes by which the Asian monsoon strengthens the climatological circulation field. We found two distinct regions, namely East Asia (the Philippines, Japan, and Mongolia) and Central Asia (India, Iran, and the Aral Sea), where there exists a strong connection between monsoon precipitation and circulation in the troposphere through the lower stratosphere.

We first summarize the results for East Asia. In the climatological field, ascent with much precipitation over a broad region from the Philippines to south Japan is evident (Figs. 2b, 2d, and 9b). In the Philippines, more precipitation occurs in strong monsoon years, causing meridional effects on circulation anomalies and wave activities over East Asia. Barotropic energy conversion in the lower troposphere coincides with northward fluxes which correspond to propagating Rossby waves. In the middle and upper troposphere, the generation of energy by diabatic heating is confirmed in the tropics. These facts imply that there are effects of the Asian monsoon in the troposphere on circulation fields in the lower stratosphere over Japan. In fact, the pressure anomaly distribution at $100 \mathrm{hPa}$ over Japan is profoundly correlated with precipita- tion over the Philippines (Fig. 10b). Thus, Rossby wave propagation in strong monsoon years in the lower troposphere is important for the connection with the stratosphere over East Asia. Ascent anomalies over the Philippines and subsequent descent anomalies in mid-latitudes occur in association with the monsoon heating. Furthermore, high pressure anomalies over Japan in the low and middle troposphere represent inactive Baiu front, being caused by active convection over the Philippine Sea. We also noted a connection with Mongolia. Over Mongolia, low pressure anomalies that occur at $850 \mathrm{hPa}$ (Fig. 8c) coincide with ascent anomalies in the middle troposphere (Fig. 3d), and precipitation anomalies are weakly positive (Fig. 3b). As discussed in Subsection 4.6, positive precipitation anomalies over both the Philippines and Mongolia are consistent with an idea of a "unified" meridional circulation anomalies over the region from low to mid-latitudes over East Asia. Over Mongolia, the stretching term in vorticity equation at $100 \mathrm{hPa}$ is negative, and fluxes in the upper troposphere are upward as a result of baroclinic energy conversion. These facts imply that the formation of high pressure anomalies over Japan is connected not only with positive precipitation anomalies near the Philippines but also with the baroclinic effect near Mongolia. Figure 14b shows the climatological field over East Asia, and Fig. 14d illustrates the "unified" meridional circulation anomalies discussed above. The climatological ascent flow over the Philippines is enhanced in strong monsoon years, and northward propagation of Rossby waves 
(a) Climatological field over Central Asia

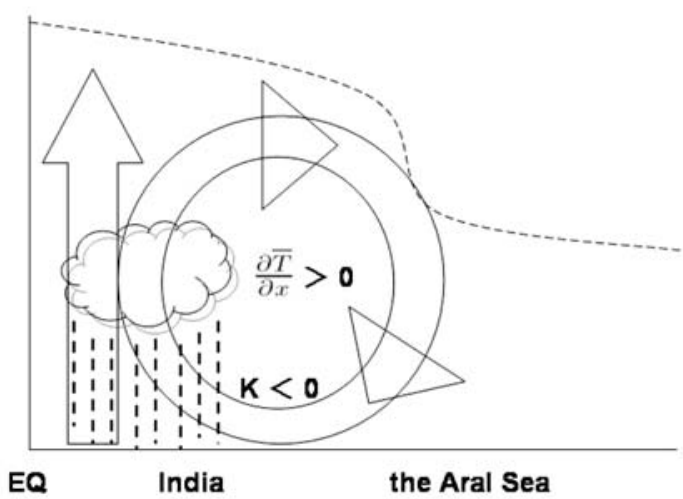

(c) Anomaly field over Central Asia

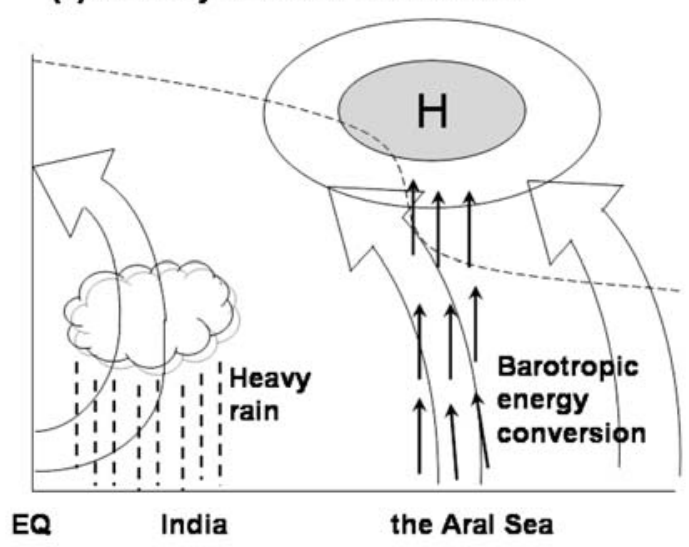

(b) Climatological field over East Asia

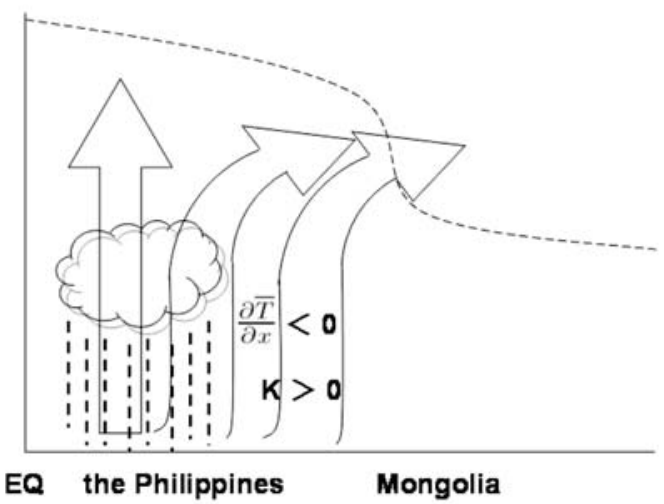

(d) Anomaly field over East Asia

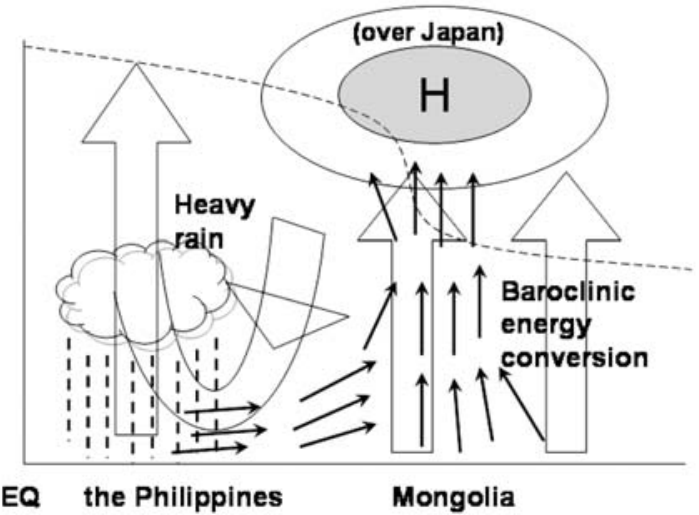

Fig. 14. Schematic diagrams of latitude-height cross-sections of climatological and anomaly fields over Central Asia (a, c) and over East Asia (b, d). $K$ and $H$ represent the total wavenumber of stationary Rossby waves and high pressure anomalies, respectively. Large white arrows show the atmospheric circulation. Thin, black arrows present the wave activity fluxes. The dashed lines show the tropopause.

occur in the lower troposphere. This Rossby wave propagation associated with the monsoon heating over the Philippines, together with the baroclinic energy conversion at mid-latitudes, causes high pressure anomalies in the lower stratosphere over Japan.

Next, we summarize the results for Central Asia. An apparent meridional circulation cell in the climatological fields is seen over the region from India through the Aral Sea (Fig. 9a). In both northern India and the Aral Sea, ascent anomalies occur in strong monsoon years. Although upward wave activity fluxes occur in mid-latitudes, northward fluxes are not seen over India. Barotropic energy conversion was found to be greater than baroclinic energy conversion in mid-latitudes, unlike in East
Asia. As discussed in Subsection 4.8, the difference in energetics between East Asia and Central Asia is primarily due to the difference in the longitudinal gradient of temperature and thus in vertical shear of the climatological meridional wind. Distribution of the total wavenumber of stationary Rossby waves (Figs. 2e and 13) also indicates different conditions between the two regions. Over Central Asia, there exists no connection between the convection at low latitudes and the high pressure anomalies in the lower stratosphere at mid-latitudes in terms of wave fluxes. We also confirmed that the correlation between the precipitation over India and vorticity at $100 \mathrm{hPa}$ is not significant (Fig. 10a). In conclusion, the formation of high pressure anomalies near the Aral Sea is associated with barotropic en- 
ergy conversion. Figures $14 \mathrm{a}$ and $14 \mathrm{c}$ illustrate the climatological and anomaly fields, respectively, over Central Asia.

Enomoto et al. (2003) revealed the relationship between descent over the Aral Sea and the circulation field over Japan by considering only barotropic effects on the climatological field. In contrast, our study shows wave divergence over Mongolia and no wave propagation from Central Asia, suggesting that the formation processes of high pressure anomalies over Japan and over Iran may differ. In fact, our results from vorticity, heat, and energy budget analyses support this interpretation. We further clarified that baroclinic effects, as well as barotropic effects, are important in forming the pressure anomalies over East Asia. Kosaka and Nakamura (2006) linked the circulation fields around Japan to strength of convection over the Philippines. Their inspection of the atmospheric structure and energy budget based on strength of convection near the Philippines also suggested that the PJ pattern might be a dynamical mode sustained through moist processes. Our results do not contradict this idea. We further emphasized the contribution of baroclinic energy conversion as well as barotropic energy conversion. Actually, we found that the baroclinic energy conversion is much greater than the barotropic energy conversion at mid-latitudes in East Asia.

We found that the lower stratospheric high pressure anomalies over Japan are related to both precipitation over the Philippines and baroclinicity over Mongolia. This result may suggest the formation of a "unified" circulation over the region from the Philippines through Japan to Mongolia. On the other hand, the high pressure anomalies over Iran are controlled profoundly by internal dynamical processes near the Aral Sea.

\section{Acknowledgments}

We thank the editor and two anonymous reviewers for their valuable comments and suggestions. The Grid Analysis and Display System (GrADS) and the Generic Mapping Tools (GMT) were utilized for drawing part of figures. This research is supported by "Global Environment Research Fund A-071" of Ministry of the Environment of Japan.

\section{References}

Boville, B. A., 1984: The influence of the Polar Night Jet on the tropospheric circulation in a GCM. $J$. Atmos. Sci., 41, 1132-1142.
Chen, P., 1995: Isentropic cross-tropopause mass exchange in the extratropics. J. Geophys. Res., 100, $16661-16673$.

Dethof, A., A. O’Neill, J. M. Slingo, and H. G. J. Smit, 1999: A mechanism for moistening the lower stratosphere involving the Asian summer monsoon. Quart. J. Roy. Meteor. Soc., 125, 1079-1106.

Ding, Q., and B. Wang, 2005: Circumglobal teleconnection in the Northern Hemisphere summer. J. Climate, 18, 3483-3505.

Ding, Y., 2007: The variability of the Asian summer monsoon. J. Meteor. Soc. Japan, 85B, 21-54.

Dunkerton, T. J., 1995: Evidence of meridional motion in the summer lower stratosphere adjacent to monsoon regions. J. Geophys. Res., 100, 16 675-16688.

Enomoto, T., B. J. Hoskins, and Y. Matsuda, 2003: The formation mechanism of the Bonin high in August. Quart. J. Roy. Meteor. Soc., 129, 157-178.

Gill, A. E., 1980: Some simple solutions for heat-induced tropical circulation. Quart. J. Roy. Meteor. Soc., 106, 447-462.

Holton, J. R., and H. C. Tan, 1980: The influence of the equatorial quasi-biennial oscillation on the global circulation at $50 \mathrm{mb}$. J. Atmos. Sci., 37, 22002208.

Holton, J. R., and H. C. Tan, 1982: The quasi-biennial oscillation in the northern hemisphere lower stratosphere. J. Meteor. Soc. Japan, 60, 140-148.

Iwao, K., and M. Takahashi, 2006: Interannual change in summertime precipitation over northeast Asia. Geophys. Res. Lett., 33, L16703, doi:10.1029/ 2006GL027 119.

Iwao, K., and M. Takahashi, 2008: A precipitation seesaw mode between northeast Asia and Siberia in summer caused by Rossby waves over the Eurasian continent. J. Climate, 21, 2401-2419.

Kalnay, E., et al., 1996: NCEP/NCAR 40-year reanalysis project. Bull. Amer. Meteor. Soc., 77, 437-471.

Kosaka, Y., and H. Nakamura, 2006: Structure and dynamics of the summertime Pacific-Japan (PJ) teleconnection pattern. Quart. J. Roy. Meteor. Soc., 132, 2009-2030.

Limpasuvan, V., and D. L. Hartmann, 1999: Eddies and the annular modes of climate variability. Geophys. Res. Lett., 26, 3133-3136.

Limpasuvan, V., and D. L. Hartmann, 2000: Wavemaintained annular modes of climate variability. J. Climate, 13, 4414-4429.

Nishii, K., and H. Nakamura, 2005: Upward and downward injection of Rossby wave activity across the tropopause: A new aspect of the tropospherestratosphere dynamical linkage. Quart. J. Roy. Meteor. Soc., 131, 545-564.

Nitta, T., 1987: Convective activities in the tropical western Pacific and their impact on the Northern Hemisphere summer circulation. J. Meteor. Soc. Japan, 65, 373-390. 
Niwano, M., and M. Takahashi, 1998: The influence of the equatorial QBO on the Northern Hemisphere winter circulation of a GCM. J. Meteor. Soc. Japan, 76, 453-461.

Rodwell, M. J., and B. J. Hoskins, 1996: Monsoons and the dynamics of deserts. Quart. J. Roy. Meteor. Soc., 122, 1385-1404.

Sato, N., and M. Takahashi, 2006: Dynamical processes related to the appearance of quasi-stationary waves on the subtropical jet in the midsummer Northern Hemisphere. J. Climate, 15, 1531-1544.

Takaya, K., and H. Nakamura, 2001: A formulation of a phase-independent wave-activity flux for stationary and migratory quasigeostrophic eddies on a zonally varying basic flow. J. Atmos. Sci., 58, 608-627.

Terao, T., 1999: Relationships between the quasistationary Rossby waves in the subtropical jet and the mass and heat transport in the northern periphery of the Tibetan High. J. Meteor. Soc. Japan, 77, 1271-1286.

Thompson, D. W. J., and J. M. Wallace, 1998: The Arctic Oscillation signature in the wintertime geopotential height and temperature fields. Geophys. Res. Lett., 25, 1297-1300.

Thompson, D. W. J., and J. M. Wallace, 2000: Annular modes in the extratropical circulation. Part I: Month-to-month variability. J. Climate, 13, 10001016.
Wakabayashi, S., and R. Kawamura, 2004: Extraction of major teleconnection patterns possibly associated with the anomalous summer climate in Japan. $J$. Meteor. Soc. Japan, 82, 1577-1588.

Webster, P. J., and S. Yang, 1992: Monsoon and ENSO: Selectively interactive systems. Quart. J. Roy. Meteor. Soc., 118, 877-926.

Xie, P., and P. A. Arkin, 1997: Global precipitation: A 17-year monthly analysis based on gauge observations, satellite estimates, and numerical model outputs. Bull. Amer. Meteor. Soc., 78, 2539-2558.

Yatagai, A., and T. Yasunari, 1995: Interannual variations of summer precipitation in the arid/semi-arid regions in China and Mongolia: Their regionality and relation to the Asian summer monsoon. $J$. Meteor. Soc. Japan, 73, 909-923.

Zhang, Q., G. Wu, and Y. Qian, 2002: The bimodality of the $100 \mathrm{hPa}$ South Asia High and its relationship to the climate anomaly over East Asia in summer. J. Meteor. Soc. Japan, 80, 733-744.

Zhang, Y., X. Kuang, W. Guo, and T. Zhou, 2006: Seasonal evolution of the upper-tropospheric westerly jet core over East Asia. Geophys. Res. Lett., 33, L11 708, doi:10.1029/2006GL026377.

Zhang, Y., M. Takahashi, and L. Guo, 2008: Analysis of the East Asian subtropical westerly jet simulated by CCSR/NIES/FRCGC coupled climate system model. J. Meteor. Soc. Japan, 86, 257-278. 